Cochrane Database of Systematic Reviews

\title{
Chlorpromazine versus penfluridol for schizophrenia (Review)
}

Nikvarz N, Vahedian M, Khalili N

Nikvarz N, Vahedian M, Khalili N.

Chlorpromazine versus penfluridol for schizophrenia.

Cochrane Database of Systematic Reviews 2017, Issue 9. Art. No.: CD011831.

DOI: 10.1002/14651858.CD011831.pub2.

www.cochranelibrary.com 
TABLE OF CONTENTS

ABSTRACT 1

PLAIN LANGUAGE SUMMARY

SUMMARY OF FINDINGS

BACKGROUND

Figure 1.

Figure 2.

OBJECTIVES

METHODS

RESULTS

Figure 3.

Figure 4.

Figure 5.

DISCUSSION

AUTHORS' CONCLUSIONS

ACKNOWLEDGEMENTS

REFERENCES

CHARACTERISTICS OF STUDIES

DATA AND ANALYSES

Analysis 1.1. Comparison 1 CHLORPROMAZINE versus PENFLURIDOL, Outcome 1 Service utilisation: 1. Hospital readmission. .

Analysis 1.2. Comparison 1 CHLORPROMAZINE versus PENFLURIDOL, Outcome 2 Adverse effects: 1a. General - needing antiparkinsonian medication.

Analysis 1.3. Comparison 1 CHLORPROMAZINE versus PENFLURIDOL, Outcome 3 Adverse effects: $1 \mathrm{~b}$. General - need to reduce antipsychotic dose due to side effects.

Analysis 1.4. Comparison 1 CHLORPROMAZINE versus PENFLURIDOL, Outcome 4 Adverse effects: $2 a$. Specific - extrapyramidal events (moderate or severe) - short term.

Analysis 1.5. Comparison 1 CHLORPROMAZINE versus PENFLURIDOL, Outcome 5 Adverse effects: $2 \mathrm{~b}$. Specific - extrapyramidal events (moderate or severe) - medium term.

Analysis 1.6. Comparison 1 CHLORPROMAZINE versus PENFLURIDOL, Outcome 6 Adverse effects: 2 c. Specific - anticholinergic (moderate or severe) - short term.

Analysis 1.7. Comparison 1 CHLORPROMAZINE versus PENFLURIDOL, Outcome 7 Adverse effects: 2 d. Specific - anticholinergic (moderate or severe) - medium term.

Analysis 1.8. Comparison 1 CHLORPROMAZINE versus PENFLURIDOL, Outcome 8 Adverse effects: 2e. Specific - central nervous system (moderate or severe) - short term.

Analysis 1.9. Comparison 1 CHLORPROMAZINE versus PENFLURIDOL, Outcome 9 Adverse effects: $2 \mathrm{f}$. Specific - central nervous system (moderate or severe) - medium term.

Analysis 1.10. Comparison 1 CHLORPROMAZINE versus PENFLURIDOL, Outcome 10 Adverse effects: $2 \mathrm{~g}$. Specific - various other effects (moderate or severe) - short term.

Analysis 1.11. Comparison 1 CHLORPROMAZINE versus PENFLURIDOL, Outcome 11 Adverse effects: $2 \mathrm{~h}$. Specific - various other effects (moderate or severe) - medium term.

Analysis 1.12. Comparison 1 CHLORPROMAZINE versus PENFLURIDOL, Outcome 12 Leaving the study early: 1a. Any reason. .... Analysis 1.13. Comparison 1 CHLORPROMAZINE versus PENFLURIDOL, Outcome 13 Leaving the study early: $1 \mathrm{~b}$. Due to adverse events.

ADDITIONAL TABLES

HISTORY

CONTRIBUTIONS OF AUTHORS

DECLARATIONS OF INTEREST

SOURCES OF SUPPORT

DIFFERENCES BETWEEN PROTOCOL AND REVIEW

INDEX TERMS 
[Intervention Review]

\section{Chlorpromazine versus penfluridol for schizophrenia}

Naemeh Nikvarz ${ }^{1}$, Mostafa Vahedian², Navid Khalili3

1Herbal and Traditional Medicines Research Center, Faculty of Pharmacy and Pharmaceutical Sciences, Kerman University of Medical Sciences, Kerman, Iran. ${ }^{2}$ Department of Biostatistics and Epidemiology, Kerman University of Medical Sciences, Kerman, Iran.

3Department of Psychiatry, Kerman University of Medical Sciences, Kerman, Iran

Contact: Navid Khalili, Department of Psychiatry, Kerman University of Medical Sciences, Shahid Beheshti Hospital, Jomhuri Eslami Blvd, Kerman, Iran. navidkhalili2000@yahoo.com.

Editorial group: Cochrane Schizophrenia Group.

Publication status and date: New, published in Issue 9, 2017.

Citation: Nikvarz N, Vahedian M, Khalili N. Chlorpromazine versus penfluridol for schizophrenia. Cochrane Database of Systematic Reviews 2017, Issue 9. Art. No.: CD011831. DOI: 10.1002/14651858.CD011831.pub2.

Copyright @ 2017 The Cochrane Collaboration. Published by John Wiley \& Sons, Ltd.

\section{A B S T R A C T}

\section{Background}

The efficacy of chlorpromazine, a benchmark antipsychotic, has not been fully assessed in direct comparison with different individual antipsychotics. Penfluridol is another old antipsychotic with a long half-life so one oral dose may last up to one week. This could confer advantage.

\section{Objectives}

To assess the clinical effects of chlorpromazine compared with penfluridol for adults with schizophrenia.

\section{Search methods}

On 31 March 2017, we searched the Cochrane Schizophrenia Group's Study-Based Register of Trials which is based on regular searches of CINAHL, BIOSIS, AMED, Embase, PubMed, MEDLINE, PsycINFO, and registries of clinical trials. There are no language, date, document type, or publication status limitations for inclusion of records in the register.

\section{Selection criteria}

We included all randomised clinical trials focusing on chlorpromazine versus penfluridol for adults with schizophrenia or related disorders. Outcomes of interest were death, service utilisation, global state, mental state, adverse effects and leaving the study early. We included trials meeting our selection criteria and reporting useable data.

\section{Data collection and analysis}

We extracted data independently. For binary outcomes, we calculated risk ratio (RR) and its 95\% confidence interval (CI), on an intentionto-treat basis. For continuous data, we planned to estimate the mean difference (MD) between groups and its $95 \% \mathrm{Cl}$. We employed a fixedeffect model for analyses. We assessed risk of bias for included studies and created a 'Summary of findings' table using GRADE.

\section{Main results}

The review includes three studies with a total of 130 participants. Short-term results for hospital admissions showed no clear difference between chlorpromazine and penfluridol ( $1 \mathrm{RCT}, \mathrm{n}=29, \mathrm{RR} 0.19,95 \% \mathrm{Cl} 0.01$ to 3.60, low-quality evidence). No clear difference in the incidence of akathisia was found at medium term ( $2 \mathrm{RCTs}, \mathrm{n}=85, \mathrm{RR} 0.19,95 \% \mathrm{Cl} 0.04$ to 1.06 , low-quality evidence), and similar numbers of participants - nearly half - from each treatment group left the study early ( $3 \mathrm{RCTs}, \mathrm{n}=130$, RR 1.21, 95\% Cl 0.83 to 1.77 , low-quality evidence). The risk of needing additional antiparkinsonian medication was less in the chlorpromazine group ( $2 \mathrm{RCTs}, \mathrm{n}=74, \mathrm{RR} 0.70,95 \% \mathrm{Cl} 0.51$ to 0.95). No useable data reported clinically important change in global or mental state. No data were reported for relapse. No deaths were reported by the trials. 


\section{Authors' conclusions}

Only three small studies provided data and the quality of reporting and evidence is low. Limited data indicate the efficacy and adverse effects profiles of chlorpromazine and penfluridol are generally similar. Penfluridol, however, may confer advantage by needing to be given only once per week. Firm conclusions are not possible without good-quality trials, and where these treatments are used, such trials are justified.

\section{PLAIN LANGUAGE SUMMARY}

\section{Chlorpromazine versus penfluridol for schizophrenia}

\section{Review question}

How effective is the antipsychotic chlorpromazine as a treatment for schizophrenia compared to penfluridol?

\section{Background}

Schizophrenia is serious mental disorder where people experience symptoms such as hallucinations and delusions, social withdrawal, decreased motivation and poor emotional response. The main treatment for schizophrenia is antipsychotic drugs. Chlorpromazine and penfluridol are widely used antipsychotics. However, different antipsychotics have different effects, and knowing the individual effects of different antipsychotics and what particular side effects they cause could help with deciding which antipsychotic to prescribe for an individual with schizophrenia. This review compares chlorpromazine with penfluridol and is one of a series of reviews comparing chlorpromazine directly with other antipsychotics.

\section{Searching}

The Information Specialist of Cochrane Schizophrenia searched their trials register in March, 2017 for trials that randomised adults with schizophrenia or related disorders to receive either chlorpromazine or penfluridol. Seven records were found and checked by the review authors

\section{Evidence found}

Only three randomised controlled trials, with a total of 130 participants met the review requirements and provided useable data. The quality of evidence available was low, no real difference was noted between chlorpromazine and penfluridol for hospital admissions, incidence of akathisia or numbers of participants leaving the study early. There were no deaths during the trials. We were unable to use the available data for global and mental state due to poor reporting, and no studies reported relapse data.

\section{Conclusions}

We can not make firm conclusions regarding the comparable effectiveness between chlorpromazine and penfluridol with such poor quality data - but penfluridol only needs to be given once per week - which could help the poor adherence to medication common with schizophrenia. Remarkably, for such old drugs, more trials that report high-quality data are needed. 


\begin{tabular}{|c|c|c|c|c|c|c|}
\hline \multicolumn{7}{|c|}{$\begin{array}{l}\text { S U M M A R Y O F F I N D I N G S } \\
\text { Summary of findings for the main comparison. }\end{array}$} \\
\hline \multicolumn{7}{|c|}{ Chlorpromazine versus Penfluridol for schizophrenia } \\
\hline \multicolumn{7}{|c|}{$\begin{array}{l}\text { Patient or population: patients with schizophrenia } \\
\text { Settings: hospital inpatients and outpatients } \\
\text { Intervention: Chlorpromazine versus penfluridol }\end{array}$} \\
\hline \multirow[t]{3}{*}{ Outcomes } & \multicolumn{2}{|c|}{$\begin{array}{l}\text { Illustrative comparative risks }{ }^{\star} \\
(95 \% \mathrm{Cl})\end{array}$} & \multirow[t]{3}{*}{$\begin{array}{l}\text { Relative effect } \\
(95 \% \mathrm{CI})\end{array}$} & \multirow{3}{*}{$\begin{array}{l}\text { No of Partici- } \\
\text { pants } \\
\text { (studies) }\end{array}$} & \multirow{3}{*}{$\begin{array}{l}\text { Quality of the } \\
\text { evidence } \\
\text { (GRADE) }\end{array}$} & \multirow[t]{3}{*}{ Comments } \\
\hline & Assumed risk ${ }^{3}$ & $\begin{array}{l}\text { Corresponding } \\
\text { risk }\end{array}$ & & & & \\
\hline & Penfluridol & $\begin{array}{l}\text { Chlorpro- } \\
\text { mazine }\end{array}$ & & & & \\
\hline $\begin{array}{l}\text { Service utilisation: hos- } \\
\text { pital admission (short } \\
\text { term) }\end{array}$ & 150 per 1000 & $\begin{array}{l}\mathbf{2 8} \text { per } 1000 \\
(1 \text { to } 540)\end{array}$ & $\begin{array}{l}\text { RR } 0.19 \text { ( } 0.01 \text { to } \\
3.60)\end{array}$ & $\begin{array}{l}29 \\
\text { (1 study) }\end{array}$ & $\begin{array}{l}\oplus \oplus \ominus \ominus \\
\text { low } \mathbf{1 , 2}\end{array}$ & \\
\hline $\begin{array}{l}\text { Global state: clinical- } \\
\text { ly important change in } \\
\text { global state }\end{array}$ & See comment & & Not estimable & $\begin{array}{l}0 \\
(0)\end{array}$ & See comment & $\begin{array}{l}\text { No studies reported 'clinically important } \\
\text { change in global state'. Change in global state } \\
\text { was measure using global state scales but all } \\
\text { data were presented without SD. }\end{array}$ \\
\hline Global state: relapse & See comment & & Not estimable & $\begin{array}{l}0 \\
(0)\end{array}$ & See comment & No studies reported this outcome. \\
\hline $\begin{array}{l}\text { Mental state: clinical- } \\
\text { ly important change in } \\
\text { mental state }\end{array}$ & See comment & & Not estimable & $\begin{array}{l}0 \\
(0)\end{array}$ & See comment & $\begin{array}{l}\text { No studies reported 'clinically important } \\
\text { change in mental state'. Change in mental } \\
\text { state was measure using mental state scales } \\
\text { but all data were presented without SD. }\end{array}$ \\
\hline $\begin{array}{l}\text { Adverse effect/event: } \\
\text { clinically important ex- } \\
\text { trapyramidal adverse } \\
\text { events - akathisia (medi- } \\
\text { um term) }\end{array}$ & 200 per 1000 & $\begin{array}{l}38 \text { per } 1000 \\
(8 \text { to } 212)\end{array}$ & $\begin{array}{l}\text { RR } 0.19 \\
(0.04 \text { to } 1.06)\end{array}$ & $\begin{array}{l}85 \\
\text { ( } 2 \text { studies) }\end{array}$ & $\begin{array}{l}\oplus \oplus \ominus \ominus \\
\text { low } \mathbf{1 , 2}\end{array}$ & $\begin{array}{l}\text { The same studies reported data for other ex- } \\
\text { trapyramidal adverse events such as rigid- } \\
\text { ity, tremor, dystonia and dyskinesia. There } \\
\text { was no observable difference between chlor- } \\
\text { promazine and penfluridol regarding any of } \\
\text { these adverse effects. }\end{array}$ \\
\hline
\end{tabular}




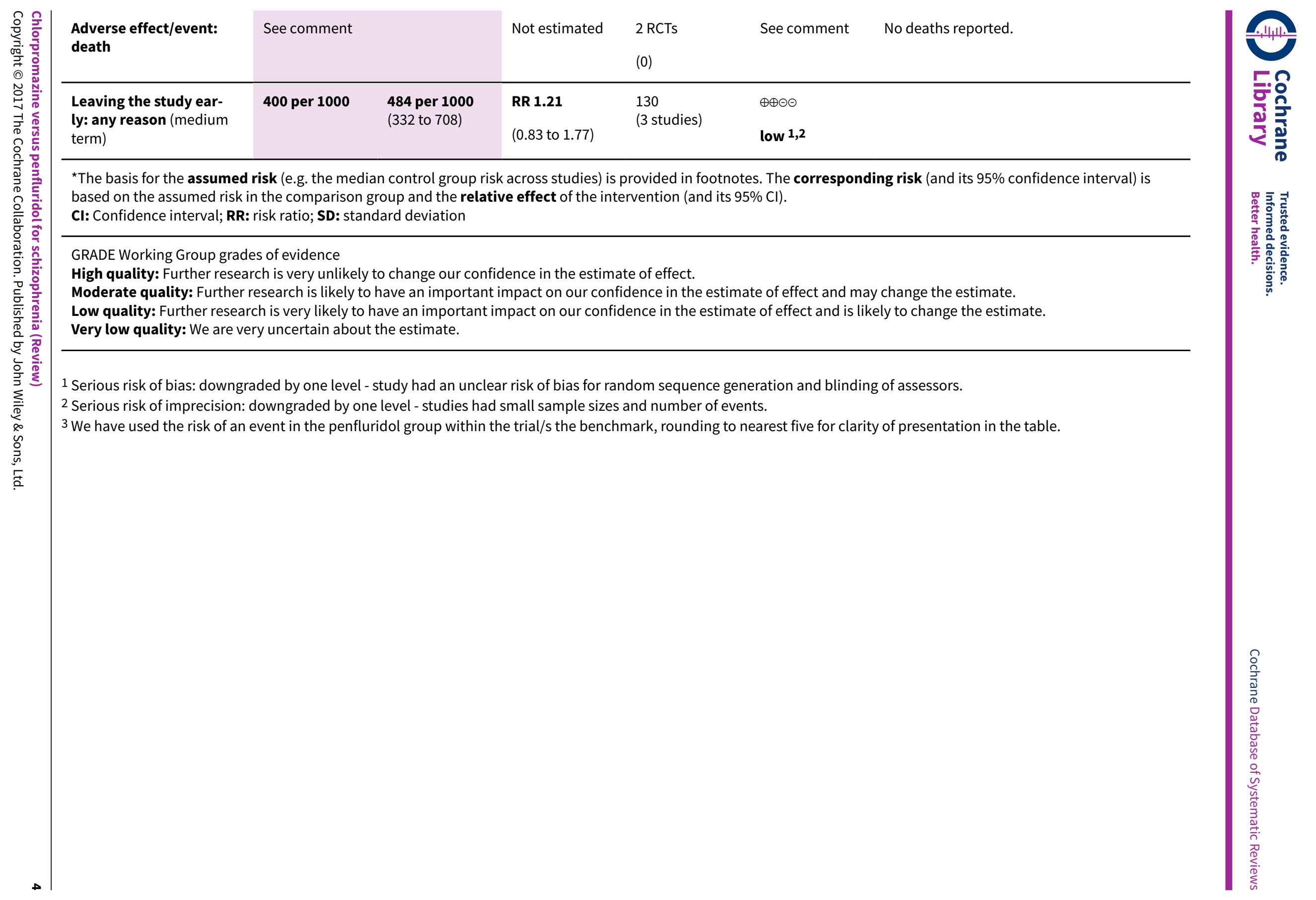




\section{B A C K G R O U N D}

\section{Description of the condition}

Schizophrenia is a chronic disabling and relapsing mental illness with a worldwide lifetime prevalence of around $1 \%$ (Almeida-Filho 1997; Perala 2007). A person with schizophrenia experiences formal thought disorder and some cognitive disturbances (Fioravant 2005; Liddle 1987). Symptoms can be divided into positive symptoms (such as delusions, hallucinations) and negative symptoms (such as poverty of speech, flattened affect, lack of pleasure, and lack of motivation) (Crow 1980). Although the symptoms of schizophrenia can be treated with antipsychotic medication, people often relapse. One of the main reasons of relapse in schizophrenia is poor compliance to drugs, often due to their adverse effects, or lack of insight to the disorder (Lindstrom 2000).

\section{Description of the intervention}

Antipsychotic drugs are the first-line treatment for symptoms of schizophrenia. Chlorpromazine is one of the essential antipsychotic drugs in the World Health Organization's list of essential drugs (WHO 2015). Chlorpromazine was introduced in the 1950s for the treatment of both acute and chronic psychoses, including schizophrenia and the manic phase of bipolar disorder, as well as amphetamine-induced psychoses. In early trials for schizophrenia, chlorpromazine in comparison with placebo showed efficacy in terms of clinical recovery, improvements in social functioning, and preventing relapse. Chlorpromazine has long been recognised as a benchmark by which other antipsychotics have been evaluated (Adams 2014). Chlorpromazine has a wide range of effects on various parts of the body; in addition to extrapyramidal side effects, it has anticholinergic and antihistaminergic effects which cause other adverse effects. To name a few, dry mouth, blurred vision, urinary retention, restlessness, tremors, facial rigidity, shuffling gait and repetitive movements of the face and/or trunk are some of its common side effects (Adams 2014). Chlorpromazine as a phenothiazine is the first of drugs named neuroleptics; after its discovery, new phenothiazine derivatives have also been introduced (Rees 1960).

Penfluridol is a long-acting antipsychotic agent first synthesised in 1963. This drug is usually administered once weekly and can be considered as a depot medication (Gerlach 1975). It is a diphenylbutylpiperdine. Similar to chlorpromazine, the side effects of penfluridol are tardive dyskinesia, extrapyramidal symptoms and sedation (Reynolds 1982).

\section{How the intervention might work}

Both chlorpromazine and penfluridol are typical antipsychotic drugs. Chlorpromazine is a phenothiazine [Subclass: aliphatic side chain; Formula: 2-chloro-10-(3-dimethylaminopropyl) phenothiazine] (Figure 1). Trade names include Largactil, Hibernal, Megaphen, Solidon and Thorazine. Since it is a dopamine antagonist, its antipsychotic property affects particular areas of the brain. 
Figure 1. Chlorpromazine structure

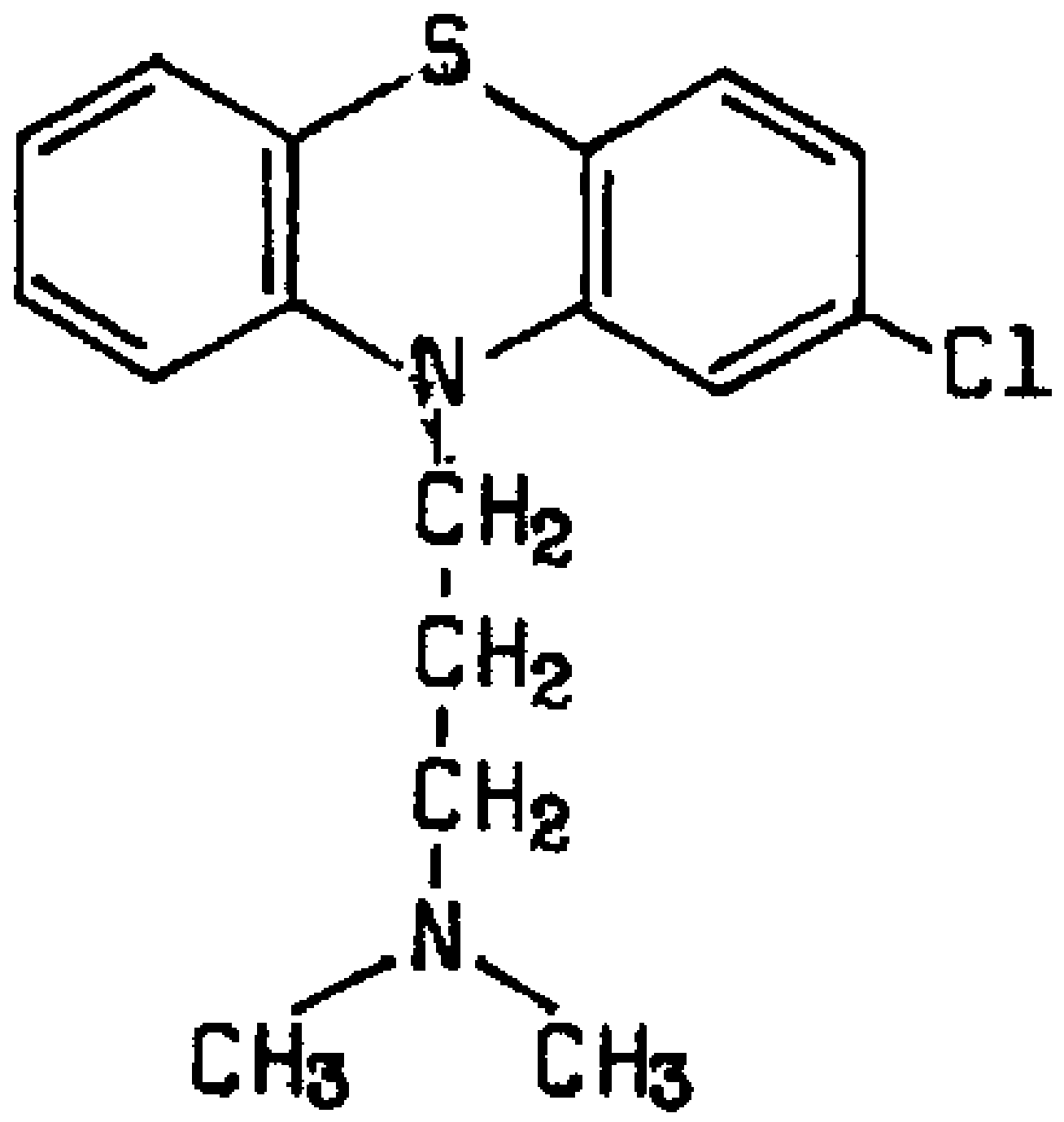

Penfluridol shows a relative antidopaminergic effect through the blocking of dopaminergic receptor membrane (Gerlach 1975; Janssen 1970). It belongs to the diphenylbutylpiperidines (Ionescu 1983; van Praag 1971) [Formula: 4-(p-chloro- ß-trifluorom-tolyl)-1-[4,4-bis(pfluorophenyl) butyl]-4-piperidinol] (Figure 2). Trade names include Semap, Sémap and Flupidol. Pimozide is the other drug in this class. Penfluridol is a tertiary amine and only slightly soluble in water (Janssen 1970). After absorption from the gastrointestinal tract, it deposits in fatty tissue from which it is gradually released, giving the prolonged duration of effects of penfluridol with its 70 hour half-life. 


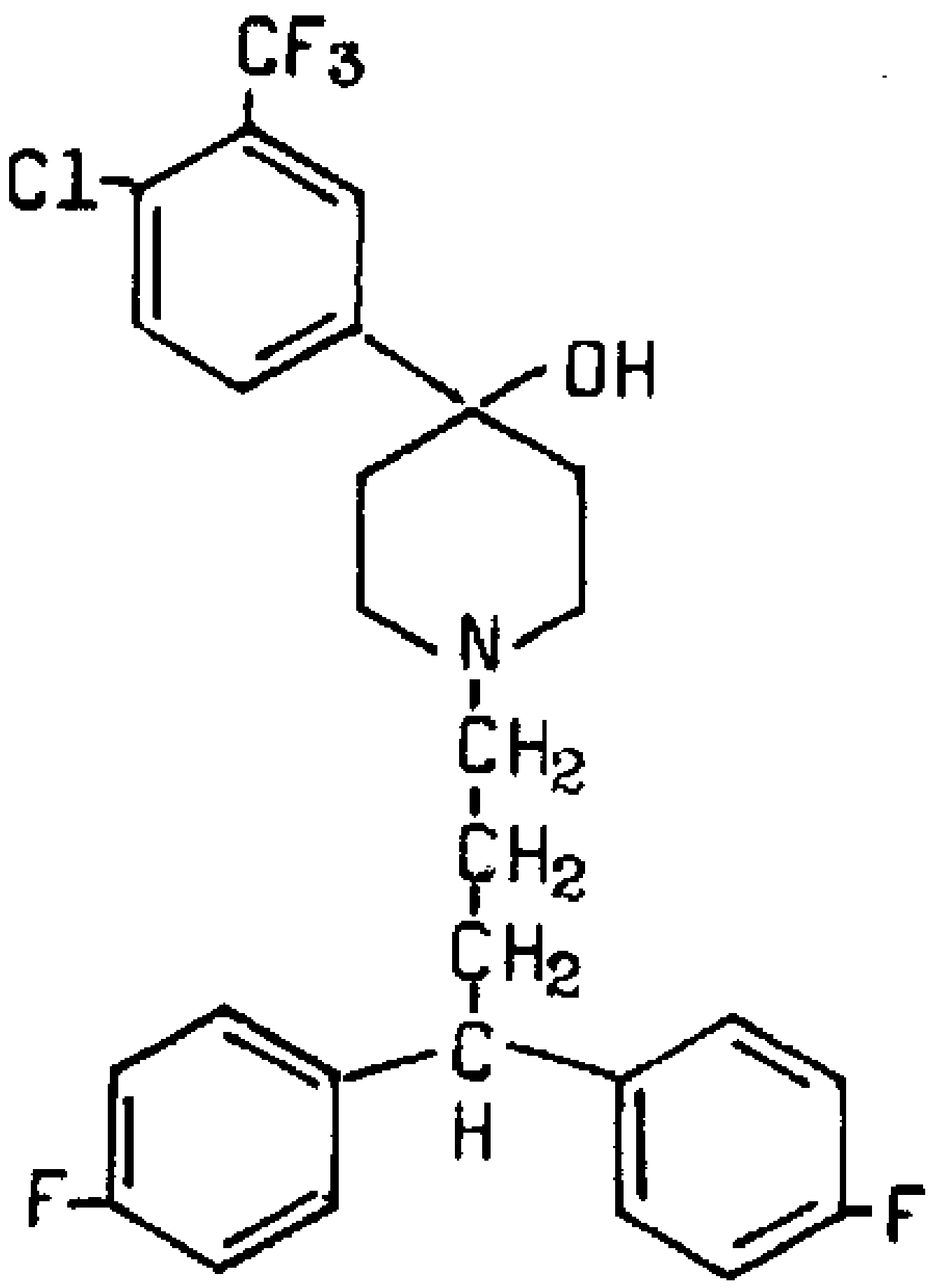

\section{Why it is important to do this review}

Chlorpromazine is widely used for psychotic disorders in Africa, India and South-East Asia. Chlorpromazine is also usually a benchmark for evaluating other drugs (Adams 2005). This review is one of a series of reviews in order to evaluate chlorpromazine in comparison with other antipsychotics so that a full overview of chlorpromazine's clinical efficacy can be completed (Table 1). There is a Cochrane systematic review of Penfluridol for schizophrenia (Soares 2006), however, the clinical profile of chlorpromazine compared with a long-acting antipsychotic such as penfluridol needs to be updated. 


\section{O B JECTIVES}

To assess the clinical effects of chlorpromazine compared with penfluridol for adults with schizophrenia.

\section{METHODS}

\section{Criteria for considering studies for this review Types of studies}

We searched for all relevant randomised controlled trials. If a trial had been described as 'double-blind' but implied randomisation, we planned to include such a trial in a sensitivity analysis ( see Sensitivity analysis). We excluded quasi-randomised studies, such as those allocating by alternate days of the week. Where people were given additional treatments within penfluridol prescription, we only included the data if the adjunct treatment was evenly distributed between groups and it was only the penfluridol that was randomised.

\section{Types of participants}

Adults, however defined, with schizophrenia or related disorders, including schizophreniform disorder and schizoaffective disorder again, by any means of diagnosis. We are interested in making sure that information is as relevant to the current care of people with schizophrenia as possible so proposed, if information was available, to clearly highlight the current clinical state (acute, early post-acute, partial remission, remission) as well as the stage (prodromal, first episode, early illness, persistent) and as to whether the studies primarily focused on people with particular problems (for example, negative symptoms, treatment-resistant illnesses).

\section{Types of interventions}

\section{Chlorpromazine}

Any dose and mode or pattern of administration.

\section{Penfluridol}

Any dose and mode or pattern of administration.

\section{Types of outcome measures}

We divided outcomes into short term (less than 12 weeks), medium term (12-52 weeks) and long term (over one year).

\section{Primary outcomes}

1. Service utilisation*

1.1 Hospital admission/readmission

\section{Global state}

2.1 Clinically important change in global state -as defined by each of the studies (short term)

\section{Adverse effects}

3.1 Clinically important extrapyramidal side effects - as defined by each of the studies

\section{Secondary outcomes}

\section{Service utilisation}

1.1 Days in hospital

\section{Global state}

2.1 Average endpoint/change score on global state scale 2.2 Relapse - as defined by each of the studies

\section{Mental state}

3.1 Clinically important change in negative symptoms - as defined by each of the studies

3.2 Average endpoint/change score on mental state scale 3.3 Average endpoint/change score in negative symptoms

\section{Behaviour}

4.1 Clinically important change in behaviour - as defined by each of the studies

4.2 Average endpoint/change score on behaviour scale

\section{Adverse effects/events}

5.1 General

5.1.1. Death-suicide/natural causes

5.1.2 At least one serious adverse effect/event

5.2 Specific (grouped by system-one expanded example given below)

5.2.1 Movement disorders

a. Any extrapyramidal side effects

b. Use of antiparkinson drugs

c. Clinically important extrapyramidal side effects-as defined by each of the studies

d. Average endpoint/change score on extrapyramidal side effects scale

\subsubsection{Anticholinergic}

5.2.3 Cardiovascular

5.2.4 Central nervous system

5.2.5 Gastrointestinal

5.2.6 Endocrine (e.g. amenorrhoea, galactorrhoea, hyperlipidaemia, hyperglycaemia, hyperinsulinaemia)

5.2.7 Haematology (e.g. haemogram, leucopenia, agranulocytosis/ neutropenia)

5.2.8 Hepatic (e.g. abnormal transaminase, abnormal liver function)

5.2.9 Metabolic

5.2.10 Various other

\section{Leaving the study early}

6.1 For any reason

6.2 Due to adverse effects

\section{Social functioning}

7.1 Clinically important change in social functioning -as defined by each of the studies

7.2 Average endpoint/change score on social functioning scale 7.3 Employment status 


\section{Economic outcomes}

\section{Quality of life/satisfaction with care, for either recipients of care or carers}

9.1 Clinically important change in quality of life/satisfaction-as defined by each of the studies

9.2 Average endpoint/change score on quality of life/satisfaction scale

\section{Cognitive functioning}

10.1 Clinically important change in cognitive functioning - as defined by each of the studies

10.2 Average endpoint/change score on cognitive functioning scale

* see Differences between protocol and review

\section{'Summary of findings' table}

We used the GRADE approach to interpret findings (Schünemann 2011); and used GRADEpro GDT to export data from our review to create a 'Summary of findings' table. This table provides outcomespecific information concerning the overall certainty of evidence from each included study in the comparison, the magnitude of effect of the interventions examined, and the sum of available data on all outcomes we rate as important to patient care and decision making. We selected the following main outcomes for inclusion in the 'Summary of findings' table:

1. Service utilisation: Hospital admission

2. Global state: Clinically important change in global state-as defined by each of the studies (short term)

3. Global state: Relapse

4. Mental state: Clinically important change in mental state -as defined by each of the studies (short term)

5. Adverse effects: Clinically important extrapyramidal side effects - as defined by each of the studies

6. Adverse effects: Death

7. Leaving the study early

\section{Search methods for identification of studies}

\section{Electronic searches}

\section{Cochrane Schizophrenia Group's Study-Based Register of Trials}

On 17 August 2015 and 31 March 2017, the Information Specialist searched the register using the following search strategy:

(Chlorpromazine AND Penfluridol) in Intervention Field of STUDY

In such a study-based register, searching the major concept retrieves all the synonyms and relevant studies because all the studies have already been organised based on their interventions and linked to the relevant topics.

This register is compiled by systematic searches of major resources (including AMED, BIOSIS, CINAHL, Embase, MEDLINE, PsycINFO, PubMed, and registries of clinical trials) and their monthly updates, handsearches, grey literature, and conference proceedings (see Group's Module). There is no language, date, document type, or publication status limitations for inclusion of records into the register.

\section{Searching other resources}

\section{Reference searching}

We inspected the references of all included studies for further relevant studies.

\section{Personal contact}

We did not contact the manufacturers of penfluridol or chlorpromazine for additional data.

\section{Data collection and analysis}

\section{Selection of studies}

Review authors NN and NK independently inspected citations from the searches and identified relevant abstracts. MV independently re-inspected a random $20 \%$ sample to ensure reliability. Where disputes arose, we acquired the full-text report for more detailed scrutiny. NN and NK obtained and inspected the full reports of the abstracts meeting the review criteria. Again, MV re-inspected a random $20 \%$ of reports in order to ensure reliable selection. If it had not been possible to resolve disagreement by discussion, we would have attempted to contact the authors of the study for clarification.

\section{Data extraction and management}

\section{Extraction}

Review author MV extracted data from all included studies. In addition, to ensure reliability, NN independently extracted data from all included studies. There were no disagreements between review authors in terms of the extracted data. If required, we would have extracted data presented only in graphs and figures whenever possible, but would have only included the data if two review authors independently had the same results.

\section{Management}

\subsection{Forms}

We extracted data onto standard, pre-designed simple forms.

\subsection{Scale-derived data}

We would have included continuous data from rating scales only if:

1. the psychometric properties of the measuring instrument have been described in a peer-reviewed journal (Marshall 2000);

2. the measuring instrument has not been written or modified by one of the trialists for that particular trial; and

3. the instrument should be a global assessment of an area of functioning and not sub-scores which are not, in themselves, validated or shown to be reliable. However there are exceptions; we would have included sub-scores from mental state scales measuring positive and negative symptoms of schizophrenia.

Ideally, the measuring instrument should either be i. a self-report or, ii. completed by an independent rater or relative (not the therapist). We realise that this is not often reported clearly; in 'Description of studies' in the Results section we would have noted whether or not this was the case.

\subsection{Endpoint versus change data}

There are advantages to both endpoint and change data. Change data can remove a component of between-person variability from 
the analysis. On the other hand, calculation of change needs two assessments (baseline and endpoint), which can be difficult in unstable and difficult to measure conditions such as schizophrenia. We decided primarily to use endpoint data, and only use change data if the former were not available. We would have combined endpoint and change data in the analysis as we prefer to use mean differences (MD) rather than standardised mean differences (SMD) (Deeks 2011).

\subsection{Skewed data}

Continuous data on clinical and social outcomes are often not normally distributed. To avoid the pitfall of applying parametric tests to non-parametric data, we planned to apply the following standards to scale data.

\section{For endpoint data from studies $N<200$}

1. If a scale started from the finite number zero, we would have subtracted the lowest possible value from the mean, and divided this by the standard deviation (SD). If this value was lower than 1 , it would have strongly suggested a skew and we would have excluded such data. If this ratio was higher than 1 but below 2 , there is a suggestion of skew. We would have entered such data and tested whether its inclusion or exclusion changed the results substantially. If these data did change the results we would have entered them as 'other data'. Finally, if the ratio was larger than 2 , we would have included these data, because skew was less likely (Altman 1996; Higgins 2011).

2. If a scale starts from a positive value (such as the Positive and Negative Syndrome Scale (PANSS), which can have values from 30 to 210) (Kay 1986), the calculation described above can be modified to take the scale starting point into account. In these cases skew is present if $2 \mathrm{SD}>$ ( $\mathrm{S}-\mathrm{S}$ min), where $\mathrm{S}$ is the mean score and ' $\mathrm{S} \mathrm{min}$ ' is the minimum score.

\section{For change data}

1. We would have entered change data as when continuous data are presented on a scale that includes a possibility of negative values (such as change data), it is difficult to tell whether data are skewed or not. We would have presented and entered change data into statistical analyses.

\subsection{Common measure}

To facilitate comparison between trials, we intended to convert variables that can be reported in different metrics, such as days in hospital (mean days per year, per week, or per month) to a common metric (e.g. mean days per month).

\subsection{Conversion of continuous to binary}

We would have made efforts to convert continuous outcome measures to dichotomous data. This can be done by identifying cut-off points on rating scales and dividing participants accordingly into 'clinically improved' or 'not clinically improved'. It is generally assumed that if there is a 50\% reduction in a scale-derived score such as the Brief Psychiatric Rating Scale (BPRS, Overall 1962) or the Positive and Negative Syndrome Scale (PANSS, Kay 1986), this could be considered as a clinically significant response (Leucht 2005a; Leucht 2005b). Had data based on these thresholds not been available, we would have used the primary cut-off presented by the original authors.

\subsection{Direction of graphs}

Where possible, we entered data in such a way that the area to the left of the line of no effect indicates a favourable outcome for chlorpromazine.

\section{Assessment of risk of bias in included studies}

MV and MV worked independently to assess risk of bias by using criteria described in the Cochrane Handbook for Systematic Reviews of Interventions (Higgins 2011a) to assess trial quality. This set of criteria is based on evidence of associations between an overestimate of effect and high risk of bias of the article, such as sequence generation, allocation concealment, blinding, incomplete outcome data and selective reporting.

If the raters had disagreed, the final rating would have been made by consensus. If inadequate details of randomisation and other characteristics of trials were provided, we would have contacted authors of the studies in order to obtain additional information. We would have reported non-concurrence in quality assessment, and if disputes arose as to which category a trial was to be allocated, again, we would have resolved these by discussion.

We noted the level of risk of bias both the Results text of the review and in the Summary of findings for the main comparison

\section{Measures of treatment effect}

\section{Binary data}

For binary outcomes, we calculated a standard estimation of the risk ratio (RR) and its 95\% confidence interval $(\mathrm{Cl})$. It has been shown that RR is more intuitive (Boissel 1999) than odds ratios (ORs) and that ORs tend to be interpreted as RRs by clinicians (Deeks 2000). The number needed to treat for an additional beneficial/harmful outcome (NNTB/NNTH) statistic with its Cls is intuitively attractive to clinicians, but is problematic both in its accurate calculation in meta-analyses and interpretation (Hutton 2009). For binary data presented in the 'Summary of findings' table, where possible, we calculated illustrative comparative risks.

\section{Continuous data}

There were no usable reported continuous data in the included studies.

\section{Unit of analysis issues}

\section{Cluster trials}

Studies increasingly employ 'cluster randomisation' (such as randomisation by clinician or practice), but analysis and pooling of clustered data poses problems. Firstly, authors often fail to account for intraclass correlation in clustered studies, leading to a 'unit of analysis' error (Divine 1992) whereby P values are spuriously low, Cls unduly narrow, and statistical significance overestimated. This causes type I errors (Bland 1997; Gulliford 1999).

If we had included cluster-randomised trials and clustering had not been accounted for in primary studies, we would have presented data in a table, with a $\left({ }^{*}\right)$ symbol to indicate the presence of a probable unit of analysis error. In subsequent versions of this review, we will seek to contact first authors of studies to obtain intra-class correlation coefficients (ICCS) for their clustered data and adjust for this by using accepted methods (Gulliford 1999). If clustering had been incorporated into the analysis of primary 
studies, we would have presented these data as if from a noncluster randomised study, but adjusted the data for the clustering effect.

We have sought statistical advice and have been advised that the binary data as presented in a report should be divided by a 'design effect'. This is calculated using the mean number of participants per cluster $(m)$ and the ICC [Design effect $=1+(m-1)^{*} I C C$ ] (Donner 2002). If the ICC was not reported we would have assumed it to be 0.1 (Ukoumunne 1999).

If cluster studies have been appropriately analysed taking into account ICCs and relevant data documented in the report, synthesis with other studies would be possible using the generic inverse variance technique.

\section{Cross-over trials}

A major concern of cross-over trials is the carry-over effect. It occurs if an effect (e.g. pharmacological, physiological or psychological) of the treatment in the first phase is carried over to the second phase. As a consequence, on entry to the second phase the participants can differ systematically from their initial state, despite a wash-out phase. For the same reason, cross-over trials are not appropriate if the condition of interest is unstable (Elbourne 2002). As both effects are very likely in severe mental illness, if cross-over trials had been included, we would only have used data of the first phase of crossover studies.

\section{Studies with multiple treatment groups}

Had a study involved more than two treatment arms, we would have presented the additional treatment arms in comparisons. If data were binary, we would simply have added and combined the data within the two-by-two table. If data were continuous, we would have combined data following the formula in section 7.7.3.8 (Combining groups) of the Cochrane Handbook for Systematic Reviews of Interventions (Higgins 2011). If the additional treatment arms were not relevant, we would not have used these data.

\section{Dealing with missing data}

\section{Overall loss of credibility}

At some degree of loss of follow-up, data must lose credibility (Xia 2009). We chose that, for any particular outcome, should more than $50 \%$ of data be unaccounted for, we would not reproduce these data or use them within analyses. If, however, more than $50 \%$ of those in one arm of a study were lost, but the total loss was less than $50 \%$, we would address this within the 'Summary of findings' table by down-rating quality. Finally, we also planned to downgrade quality within the 'Summary of findings' table should the loss be $25 \%$ to $50 \%$ in total.

\section{Binary}

In the case where attrition for a binary outcome was between $0 \%$ and $50 \%$ and where these data were not clearly described, we planned to present data on a 'once-randomised-always-analyse' basis (an intention-to-treat analysis (ITT)). Those leaving the study early would all have been assumed to have the same rates of negative outcome as those who completed. We would have used the rate of those who stayed in the study - in that particular arm of the trial - and applied this also to those who did not. We planned to undertake a sensitivity analysis to test how prone the primary outcomes were to change when data only from people who completed the study to that point were compared to the intentionto-treat analysis using the above assumptions.

\section{Continuous}

\subsection{Attrition}

In cases where attrition for a continuous outcome was between $0 \%$ and $50 \%$, and data only from people who completed the study to that point were reported, we would have reproduced such data.

\subsection{Standard deviations}

If standard deviations (SDs) were not reported, we would first have tried to obtain the missing values from the authors. If not available, where there were missing measures of variance for continuous data, but an exact standard error (SE) and confidence intervals available for group means, and either a $P$ value or $t$ value available for differences in mean, we can calculate them according to the rules described in the Cochrane Handbook for Systematic Reviews of Interventions (Higgins 2011): When only the $\mathrm{SE}$ is reported, SDs are calculated by the formula $\mathrm{SD}=\mathrm{SE}$ * square root (n). Chapters 7.7.3 and 16.1.3 of the Cochrane Handbook for Systematic Reviews of Interventions (Higgins 2011) present detailed formulae for estimating SDs from $P$ values, $t$ or $F$ values, confidence intervals, ranges or other statistics. If these formulae do not apply, we can calculate the SDs according to a validated imputation method which is based on the SDs of the other included studies (Furukawa 2006). Although some of these imputation strategies can introduce error, the alternative would be to exclude a given study's outcome and thus to lose information. We nevertheless would examine the validity of the imputations in a sensitivity analysis excluding imputed values.

\subsection{Assumptions about participants who left the trials early or were lost to follow-up}

Various methods are available to account for participants who leave the trials early or are lost to follow-up. Some trials just present the results of study completers, others use the method of last observation carried forward (LOCF), while more recently methods such as multiple imputation or mixed effects models for repeated measurements (MMRM) have become more of a standard. While the latter methods seem to be somewhat better than LOCF (Leon 2006), we feel that the high percentage of participants leaving the studies early and differences in the reasons for leaving the studies early between groups is often the core problem in randomised schizophrenia trials. We therefore decided we would not exclude studies based on the statistical approach used. However, we would preferably have used the more sophisticated approaches. For example, MMRM or multiple-imputation is preferred to LOCF and we would only present completer analyses if some kind of ITT data were not available at all. Moreover, we addressed this issue in the 'Risk of bias' tool.

\section{Assessment of heterogeneity}

\section{Clinical heterogeneity}

We considered all included studies initially, without seeing comparison data, to judge clinical heterogeneity. We simply inspected all studies for clearly outlying people or situations which we had not predicted would arise. If such situations or participant groups had arisen, we would have discussed any issues. 


\section{Methodological heterogeneity}

We considered all included studies initially, without seeing comparison data, to judge methodological heterogeneity. We simply inspected all studies for clearly outlying methods which we had not predicted would arise. If such methodological outliers had arisen, we would have discussed any issues.

\section{Statistical heterogeneity}

\subsection{Visual inspection}

We visually inspected graphs to investigate the possibility of statistical heterogeneity.

\subsection{Employing the $I^{2}$ statistic}

We investigated heterogeneity between studies by considering the $\mathrm{I}^{2}$ method alongside the $\mathrm{Chi}^{2} \mathrm{P}$ value. The $\mathrm{I}^{2}$ provides an estimate of the percentage of inconsistency thought to be due to chance (Higgins 2003). The importance of the observed value of $1^{2}$ depends on i. magnitude and direction of effects and ii. strength of evidence for heterogeneity (e.g. $\mathrm{P}$ value from $\mathrm{Chi}^{2}$ test, or a confidence interval for $\mathrm{1}^{2}$ ). We would have considered an $\mathrm{I}^{2}$ estimate greater than or equal to around $50 \%$ accompanied by a statistically significant $\mathrm{Chi}^{2}$ statistic, as evidence of substantial levels of heterogeneity (Section 9.5.2, Deeks 2011). If substantial levels of heterogeneity had been found in the primary outcome, we would have explored reasons for heterogeneity (Subgroup analysis and investigation of heterogeneity).

\section{Assessment of reporting biases}

Reporting biases arise when the dissemination of research findings is influenced by the nature and direction of results (Egger 1997). These are described in section 10.1 of the Cochrane Handbook for Systematic Reviews of Interventions (Sterne 2011).

\section{Protocol versus full study}

We tried to locate protocols of included randomised trials. If the protocol was available, we compared outcomes in the protocol and in the published report. If the protocol was not available, we compared outcomes listed in the methods section of the trial report with actually reported results.

\section{Funnel plot}

We are aware that funnel plots may be useful in investigating reporting biases but are of limited power to detect small-study effects. We planned not to use funnel plots for outcomes where there were 10 or fewer studies, or where all studies were of similar size. In other cases, where funnel plots were possible, we would have sought statistical advice in their interpretation.

\section{Data synthesis}

We understand that there is no closed argument for preference for use of fixed-effect or random-effects models. The random-effects method incorporates an assumption that the different studies are estimating different, yet related, intervention effects. This often seems to be true to us and the random-effects model takes into account differences between studies even if there is no statistically significant heterogeneity. There is, however, a disadvantage to the random-effects model. It puts added weight onto small studies which often are the most biased ones. Depending on the direction of effect these studies can either inflate or deflate the effect size. We chose fixed model for all analyses.

\section{Subgroup analysis and investigation of heterogeneity}

\section{Subgroup analyses}

\subsection{Primary outcomes}

No subgroup analysis was anticipated.

\section{Investigation of heterogeneity}

If inconsistency was high, we would have reported it. First, we would have investigated whether data had been entered correctly. Second, if data were correct, we would have visually inspected the graph and successively removed outlying studies to see if homogeneity was restored. For this review, we decided that should this occur with data contributing to the summary finding of no more than around $10 \%$ of the total weighting, we would present the data. If not, we would not pool these data, but discuss any issues. We know of no supporting research for this $10 \%$ cut-off but are investigating use of prediction intervals as an alternative to this unsatisfactory state.

If unanticipated clinical or methodological heterogeneity had been obvious we would simply have stated hypotheses regarding these for future reviews or versions of this review. We did not anticipate undertaking analyses relating to these.

\section{Sensitivity analysis}

If substantial differences had been noted in the direction or precision of effect estimates in any of the sensitivity analyses listed below, we would not have pooled data from the excluded trials with the other trials contributing to the outcome, but presented them separately as 'other data'.

\section{Implication of randomisation}

We would have included trials in a sensitivity analysis if they had been described in some way as to imply randomisation. For the primary outcomes, if there had been no substantive difference when we added the implied randomised studies to those with better descriptions of randomisation, then we would have employed all data from these studies.

\section{Assumptions for lost binary data}

Where assumptions had to be made regarding people lost to followup (see Dealing with missing data), we would have compared the findings of the primary outcomes when we used our assumptions and when we used data only from people who completed the study to that point. If there was a substantial difference, we would have reported results and discussed them but continued to employ our assumption.

\section{Risk of bias}

For the primary outcome, we would have analysed the effects of excluding trials that were judged to be at high risk of bias across one or more of the domains of randomisation (see Assessment of risk of bias in included studies). If the exclusion of trials at high risk of bias had not substantially altered the direction of effect or the precision of the effect estimates, then we would have included data from these trials in the analysis. 


\section{Imputed values}

If we had included cluster trials, we would have undertaken a sensitivity analysis to assess the effects of including data from trials where we used imputed values for ICC in calculating the design effect in cluster-randomised trials.

\section{Fixed-effect or random-effects}

We synthesised all data using a fixed-effect model. However, we also synthesised data for the primary outcome using a randomeffects model to evaluate whether this altered the significance of the results. If there had been a substantial difference, we would have reported this.

\section{RE S U L T S}

\section{Description of studies}

Please see Characteristics of included studies and Characteristics of excluded studies.

\section{Results of the search}

Details of the search results are illustrated in the PRISMA table (Figure 3). 
Figure 3. Study flow diagram.

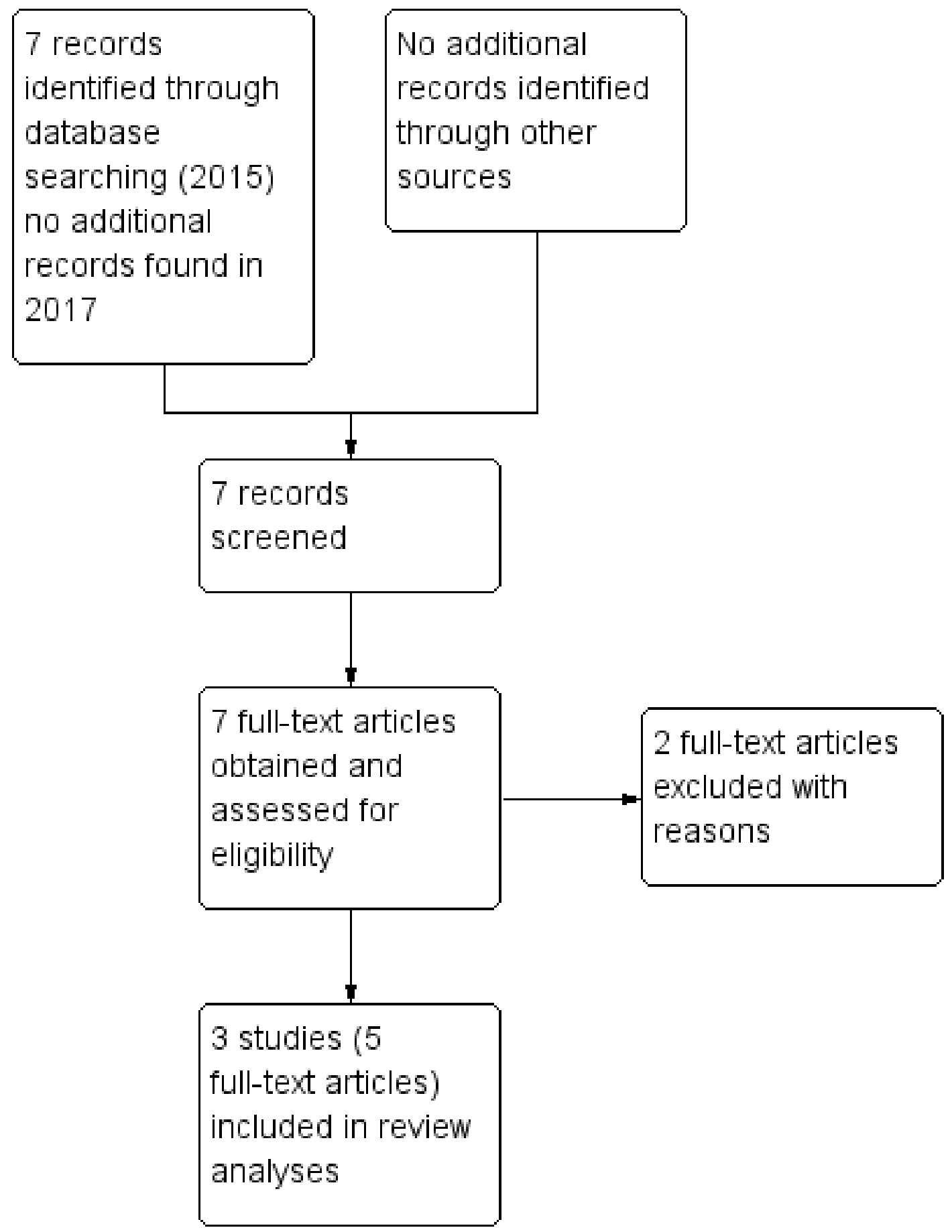

In the original search we found seven reports that were potentially relevant. There were no duplicates. We inspected full text of these reports and then grouped these into trials where several reports referred to the same trial. After excluding two trials, we included three trials (five reports).

\section{Included studies}

\section{Duration}

Duration of studies ranged from 13 to 52 weeks. Results of Chouinard 1977 were reported in three separate published articles. Two of them contain results of participants receiving the chlorpromazine or penfluridol for an inpatient phase of three weeks and the other has results of an outpatient follow-up phase which lasted 10 weeks. Wang 1982 was a medium-term trial of 20 weeks and, finally, Claghorn 1979 was for a total of 52 weeks. 


\section{Participants}

A total of 130 people aged 19 to 60 years participated in the studies.

All participants were diagnosed with schizophrenia. Participants in Chouinard 1977 were classified as paranoid or non-paranoid subtype based on the Diagnostic and Statistical Manual of Mental Disorders_II (DSM-II criteria). Wang 1982 reported no criteria for diagnosis of schizophrenia. The diagnostic criteria for Claghorn 1979 are not clear. All participants had a history of chronic schizophrenia with the people in the Claghorn 1979 study being particularly unwell with a duration of illness in the decades and even the particular episode of illness being between eight and 10 years long.

Participants in Wang 1982 were all males. Claghorn 1979 and Chouinard 1977 included both men and women.

\section{Setting}

Chouinard 1977 had an inpatient setting for three weeks, followed by a 10-week outpatient phase. Wang 1982 included both inpatients and outpatients. Claghorn 1979, dealing with a group of very ill people, was conducted all in hospital.

\section{Intervention}

Both intervention drugs were administered orally.

\subsection{Chlorpromazine}

The starting dose and maximum doses of chlorpromazine in Wang 1982 were $415 \mathrm{mg} /$ day and $1050 \mathrm{mg} /$ day, respectively. Chouinard 1977 prescribed chlorpromazine at dose of $300 \mathrm{mg}$ /day during the first week, $600 \mathrm{mg} /$ day in the second week and $900 \mathrm{mg} /$ day during the third week, and continued the last dose in the 10-week follow- up phase (the mean dose was $650 \mathrm{mg} /$ day). Although there were higher doses used, the final mean dose in Claghorn 1979 settled at $300 \mathrm{mg} /$ day.

\subsection{Penfluridol}

The initial dose, and maximum doses of penfluridol Wang 1982 were $60 \mathrm{mg} /$ week and $140 \mathrm{mg} /$ week, respectively. Chouinard 1977 prescribed penfluridol at single dose of $40 \mathrm{mg}$ in the first week, $80 \mathrm{mg}$ in the second week and $120 \mathrm{mg}$ during the third week and continued the last dose in the 10-week follow-up phase (the mean dose was $102 \mathrm{mg} /$ week). A similar regimen was adopted by Claghorn 1979, with the final mean dose being $74 \mathrm{mg} /$ week.

\section{Outcomes and outcome scales}

Studies reported dichotomous (binary) and continuous outcomes; however, all scale data were impossible to use as, either, means were presented without SD or attrition was over $50 \%$ (please see Dealing with missing data). No included study reported economic outcomes, and effects of interventions on quality of life, employment status or cognitive functioning.

\section{Excluded studies}

We excluded two studies. One was a quasi-randomised study (Bao 1988). We initially had excluded Claghorn 1979 as less than $50 \%$ of people completed the entire course of the trial, but found that some adverse effects and the number actually leaving were reported on $100 \%$ of people; as a result, this study is now included. Li 1987 also seemed to have high attrition, but in addition, the number of people in each group was not mentioned. Therefore we excluded this study.

\section{Risk of bias in included studies}

See Figure 4 and Figure 5 .

Figure 4. 'Risk of bias' graph: review authors' judgements about each risk of bias item presented as percentages across all included studies.

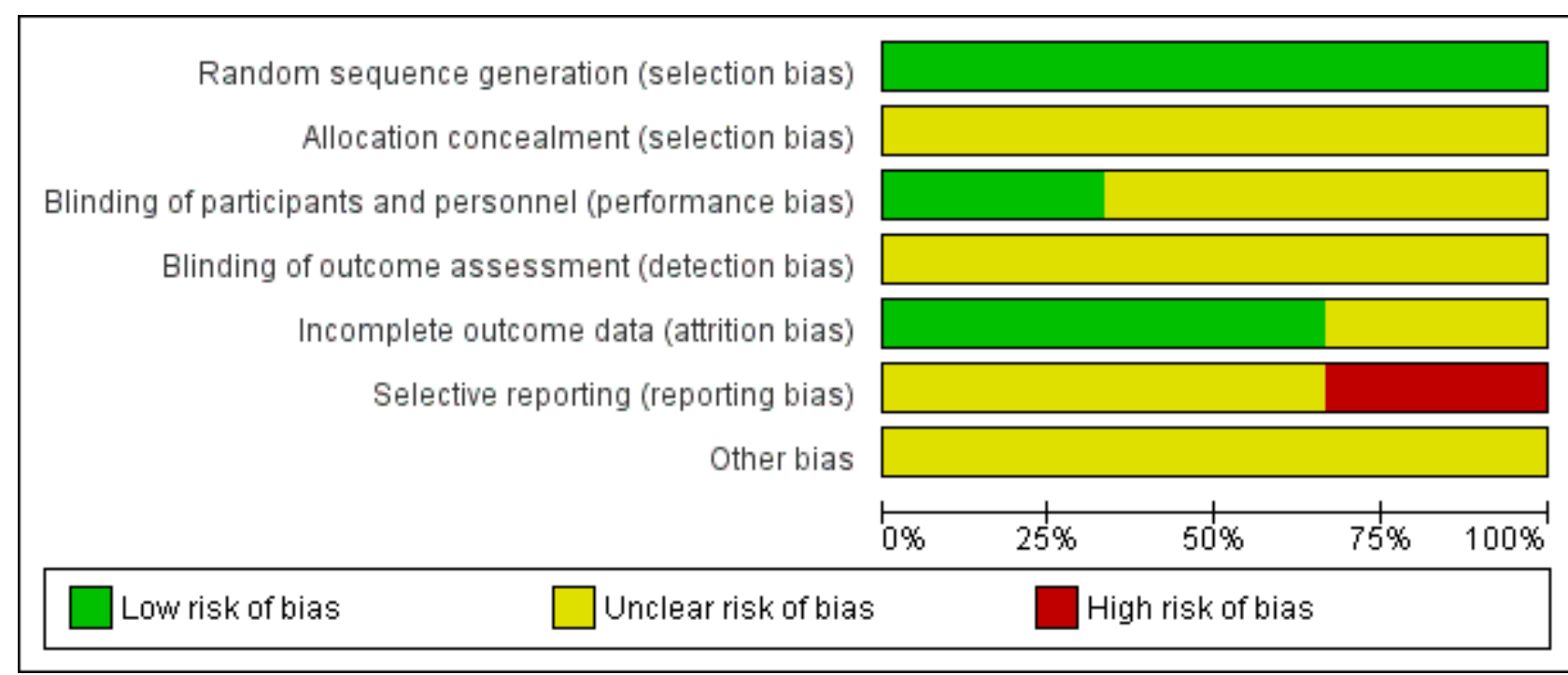


Figure 5. 'Risk of bias' summary: review authors' judgements about each risk of bias item for each included study.

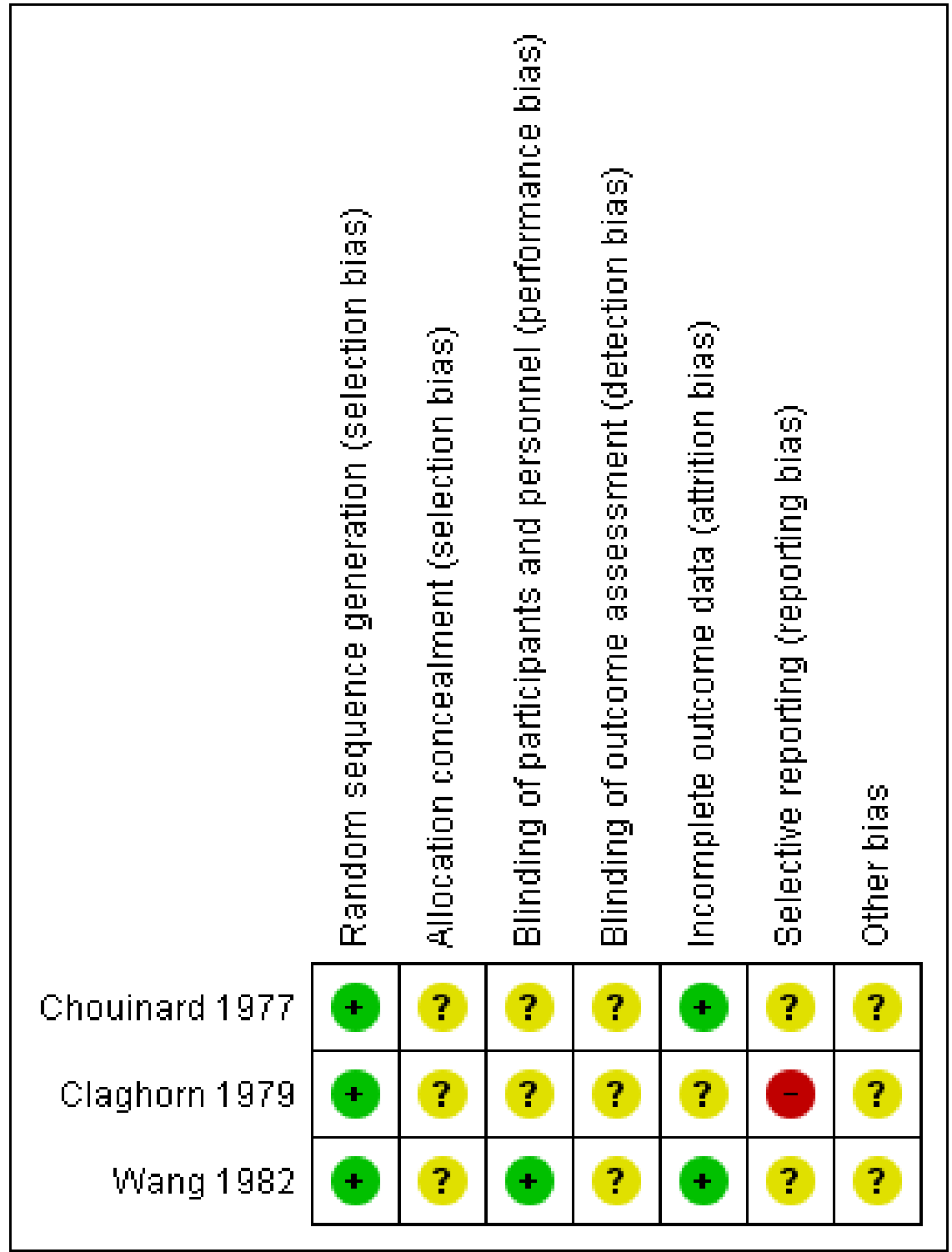

\section{Allocation}

None of the included studies described the methods used to generate random allocation, although Claghorn 1979 used block randomisation. Having said that, the Claghorn 1979 study, conscious of how allocation can still result in imbalanced groups, reported on differences in distribution of illness duration and sex. There was an implication from the writing in this study that the authors understood the randomisation procedure. We have no information from these old studies about allocation concealment.

\section{Blinding}

All three included trials used a double-blind design. Chouinard 1977 had an unclear risk of bias as reports did not explain how they used a double-blind method and how successful their attempts at blinding were. Claghorn 1979 used placebo tablets to mask that participants in one group really only got one active dose per week whereas those allocated to chlorpromazine were given active compound daily. Wang 1982 described their method of blinding. In this study all patients received identical appearing capsules on a special "blister pack" medication card allowing the patient to take the medication on a twice-a-day schedule. We rated Wang 1982 as low risk of bias for performance bias as they had described the methods used to ensure blinding of participants and personnel.

\section{Incomplete outcome data}

This was not a major issue in two of the trials. Claghorn 1979, however, had high attrition that was clearly described.

\section{Selective reporting}

We felt that both Chouinard 1977 and Wang 1982 carry at least an 'unclear' risk of bias for selective reporting as quite a few outcomes were not clearly reported. Claghorn 1979, however, we thought, should be rated as 'high' risk as there was clear selective reporting of adverse effects. We recognise that when extensive investigations are undertaken this can generate a very long list of rare adverse effects that is cumbersome to reproduce in the published report. 
With online storage of data this becomes less of a problem and we may be judging Claghorn 1979 by standards of three decades beyond its publication. However, we think, even in 1979, inclusion of extensive lists of adverse effects was not rare and such a table would have been reassuring to the reader that rare but important effects had not been under-reported.

\section{Other potential sources of bias}

All three studies had an unclear risk of bias for other potential sources of bias.

\section{Effects of interventions}

\section{See: Summary of findings for the main comparison}

\section{COMPARISON 1. Chlorpromazine versus penfluridol}

\section{Service utilisation: hospital readmission}

We identified one short-term study $(n=29)$ reporting data for this outcome. We did not find evidence of a clear difference between chlorpromazine and penfluridol (risk ratio (RR) 0.19, 95\% confidence interval $(\mathrm{Cl}) 0.01$ to 3.60 , low-quality evidence; Analysis 1.1).

\subsection{Adverse effects: 1a. General - needing antiparkinsonian medication}

Short-term results from Chouinard 1977 showed no observable difference between chlorpromazine and penfluridol for numbers of participants needing antiparkinsonian medication ( $1 \mathrm{RCT}, \mathrm{n}=33$, RR $0.82,95 \% \mathrm{Cl} 0.46$ to 1.46 ) and Wang 1982 however found evidence that chlorpromazine had a favourable effect in the medium term (1 RCT, $\mathrm{n}=41$, RR $0.63,95 \% \mathrm{Cl} 0.43$ to 0.91 ). Overall, there was suggestion that use of chlorpromazine carried less risk of needing additional medication for movement disorder adverse effects (2 RCTs, $\mathrm{n}=74$, RR 0.70, $95 \% \mathrm{Cl} 0.51$ to 0.95 ; Analysis 1.2).

\subsection{Adverse effects: $1 b$. General - need to reduce antipsychotic dose due to adverse effects}

Similar numbers of participants from each group needed a reduction in their antipsychotic dose to alleviate adverse effects ( 1 $\mathrm{RCT}, \mathrm{n}=33$, RR $0.74,95 \% \mathrm{Cl} 0.26$ to 2.06 ; Analysis 1.3 ).

\subsection{Adverse effects: $2 a$. Specific - extrapyramidal events (moderate or severe) - short term}

Chouinard 1977 assessed extrapyramidal adverse effects at three weeks. No incidences of akathisia, dyskinesia, dystonia or tremor were observed. Two participants receiving penfluridol experienced rigidity, while no rigidity occurred in the chlorpromazine group, however, these data do not show a substantial difference between chlorpromazine and penfluridol for this outcome ( $1 \mathrm{RCT}, \mathrm{n}=33$, RR $0.15,95 \% \mathrm{Cl} 0.01$ to 2.90 ; Analysis 1.4 ).

\subsection{Adverse effects: $2 b$. Specific - extrapyramidal events (moderate or severe) - medium term}

Overall, no differences between chlorpromazine and penfluridol were evident for extrapyramidal events (Analysis 1.5).

\subsection{1 akathisia}

Two studies reported data for akathisia, there was not a clear difference in effect between chlorpromazine and penfluridol (2 RCTs, n = 85, RR 0.19, 95\% Cl 0.04 to 1.06, low-quality evidence).

\subsection{2 dyskinsia}

Two studies reported data for dyskinesia, there was not a clear difference in effect between chlorpromazine and penfluridol (2 RCTs, $\mathrm{n}=85$, RR $0.97,95 \% \mathrm{Cl} 0.14$ to 6.52 ).

\subsection{3 dystonia}

One study reported data for dystonia, with one person from each group experiencing dystonia ( $1 \mathrm{RCT}, \mathrm{n}=29, \mathrm{RR} 0.93,95 \% \mathrm{Cl} 0.06$ to 13.54).

\subsection{4 muscle spasm}

One study $(n=56)$ reported data for muscle spasm, there was not a clear difference between chlorpromazine and penfluridol (RR 3.00, $95 \% \mathrm{Cl} 0.13$ to 70.64$)$.

\subsection{5 rigidity}

Two studies $(n=70)$ reported data for this outcome, there was not a clear difference in effect between chlorpromazine and penfluridol (RR $0.22,95 \% \mathrm{Cl} 0.04$ to 1.20 ).

\subsection{6 tremor}

Two studies $(n=85)$ reported data for this outcome, there was not a clear difference in effect between chlorpromazine and penfluridol RR $0.70,95 \% \mathrm{Cl} 0.14$ to 3.43 ).

\subsection{Adverse effects: $2 c$. Specific - anticholinergic (moderate or severe) - short term}

One study provided data for anticholinergic effects. Overall, no differences between chlorpromazine and penfluridol were evident for anticholingeric adverse effects in the short term (Analysis 1.6).

\subsection{1 constipation}

Six people receiving chlorpromazine and one person receiving penfluridol experienced constipation ( $1 \mathrm{RCT}, \mathrm{n}=33, \mathrm{RR} 4.42,95 \% \mathrm{Cl}$ 0.60 to 32.71 ).

\subsection{2 dry mouth}

Only one person in the chlorpromazine group experienced dry mouth (1 RCT, $\mathrm{n}=33$, RR $2.25,95 \% \mathrm{Cl} 0.10$ to 51.46 ).

\subsection{3 increased salivation}

One person receiving penfluridol experienced an increase in salivation (1 RCT, $\mathrm{n}=33$, RR $0.25,95 \% \mathrm{Cl} 0.01$ to 5.72 ).

\subsection{Adverse effects: $2 d$. Specific - anticholinergic (moderate or severe) - medium term}

Again, only one study reported data. Overall, no differences between chlorpromazine and penfluridol were evident for anticholingeric adverse effects in the medium term (Analysis 1.7).

\subsection{1 blurred vision}

No people receiving chlorpromazine and one receiving penfluridol experienced blurred vision ( $1 \mathrm{RCT}, \mathrm{n}=29$, RR $0.31,95 \% \mathrm{Cl} 0.01$ to 7.09).

\subsection{2 constipation}

Four people in the chlorpromazine group and one receiving penfluridol experienced constipation ( $1 \mathrm{RCT}, \mathrm{n}=29, \mathrm{RR} 3.73,95 \% \mathrm{Cl}$ 0.47 to 29.49 ) 


\subsection{3 dry mouth}

One person receiving chlorpromazine experienced dry mouth (1 $\mathrm{RCT}, \mathrm{n}=29$, RR 2.81, 95\% Cl 0.12 to 63.83).

\subsection{Adverse effects: 2e. Specific - central nervous system (moderate or severe) - short term}

Data from one study found no differences between chlorpromazine and penfluridol were evident for anticholingeric adverse effects in the short term (Analysis 1.8).

\subsection{1 agitation}

One person receiving chlorpromazine became agitated in the short term ( $1 \mathrm{RCT}, \mathrm{n}=33$, RR 2.25, $95 \% \mathrm{Cl} 0.10$ to 51.46 ).

\subsection{2. drowsiness}

Flve people receiving chlorpromazine became drowsy ( $1 \mathrm{RCT}, \mathrm{n}=$ 33, RR 8.25, $95 \% \mathrm{Cl} 0.49$ to 137.94 ).

\subsection{3 dizziness}

One participant in the chlorpromazine group and three in the penfluridol group experienced dizziness ( $1 \mathrm{RCT}, \mathrm{n}=33, \mathrm{RR} 0.25,95 \%$ $\mathrm{Cl} 0.03$ to 2.12 ).

\subsection{4 insomnia}

One person receiving chlorpromazine experienced insomnia (1 RCT, $\mathrm{n}=33$, RR $2.25,95 \% \mathrm{Cl} 0.10$ to 51.46$)$.

\subsection{Adverse effects: $2 f$. Specific - central nervous system (moderate or severe) - medium term}

Two studies reported central nervous system effects data for the medium term, there was no clear differences between the two treatments for specific central nervous system effects.

\subsection{1 drowsiness}

Two studies showed no evidence of a clear difference between the two treatments for drowsiness (2 RCTs, $n=85$, RR 1.05, 95\% Cl 0.54 to 2.05$)$.

\subsection{2 dizziness}

One study reported data for dizziness. One person in the chlorpromazine group and two in the penfluridol group experienced dizziness ( $1 \mathrm{RCT}, \mathrm{n}=29$, $\mathrm{RR} 0.47,95 \% \mathrm{Cl} 0.05$ to 4.60 ).

\subsection{3 excitement}

One study reported data for excitement. One person in the chlorpromazine group experienced excitement ( $1 \mathrm{RCT}, \mathrm{n}=29$, RR $2.81,95 \% \mathrm{Cl} 0.12$ to 63.83$)$.

\subsection{4 faintness}

One study reported data for faintness. Two participants from each group experienced faintness ( $1 \mathrm{RCT}, \mathrm{n}=29$, RR $0.93,95 \% \mathrm{Cl} 0.15$ to 5.76).

\subsection{5 insomnia}

Two studies reported data for insomnia. There was evidence of a clear difference, favouring chlorpromazine (2 RCTs, $n=85$, RR 0.17 , $95 \% \mathrm{Cl} 0.03$ to 0.93$)$.

\subsection{Adverse effects: 2 g. Specific - various other effects (moderate or severe) - short term}

Two studies provided data for various other effects. One reported on heartburn and the other reported on systemic allergic reaction. Chlorpromazine was no different in its effect compared to penfluridol for various other short-term effects (Analysis 1.10).

\subsection{1 heartburn}

One study $(n=33)$ provided data for heartburn. No one experienced heartburn in either group.

\subsection{2 increased alkaline phosphatase, bilirubin, SGOT (serum glutamic oxaloacetic transaminase)}

One study found no evidence of a difference between the two treatments ( $1 \mathrm{RCT}, \mathrm{n}=56$, RR $0.3395 \% \mathrm{Cl} 0.01$ to 7.85 )

\subsubsection{Systemic allergic reaction}

One study provided data. Three people in the chlorpromazine group experienced systemic allergic reaction ( $1 R C T, n=33, R R 5.25$, $95 \% \mathrm{Cl} 0.29$ to 94.14$)$.

\subsection{Adverse effects: $2 \mathrm{~h}$. Specific - various other effects (moderate or severe) - medium term}

Various other adverse effects were measured in the medium term by one study. No clear difference was seen between the two treatments for any of these effects Analysis 1.11.

\subsection{1 depression}

(1 RCT, $n=29$, RR 0.19, 95\% Cl 0.01 to 3.60 ).

\subsection{2 decreased sexual drive}

(1 RCT, $n=29$, RR $0.47,95 \% \mathrm{Cl} 0.05$ to 4.60 ).

\subsection{3 impotence}

(1 RCT, $\mathrm{n}=29$, RR 2.81, 95\% $\mathrm{Cl} 0.12$ to 63.83 ).

\subsection{4 photosensitivity}

(1 RCT, $\mathrm{n}=29$, RR $2.81,95 \% \mathrm{Cl} 0.12$ to 63.83 ).

\subsection{5 poor appetite}

(1 RCT, $n=29$, RR 0.93, 95\% Cl 0.06 to 13.54).

\subsection{Leaving the study early: 1a. Any reason}

Pooled data from three studies showed no clear medium-term differences between penfluridol and chlorpromazine ( 3 RCTs, $n=$ 130, RR 1.21 . $95 \% \mathrm{Cl} 0.83$ to 1.77 , low-quality evidence; Analysis $1.12)$.

\subsection{Leaving the study early: $1 b$. Due to adverse events}

Two studies found no clear differences, in either short or medium term, when leaving early was due to adverse effects (Analysis 1.13)

\section{DISCUSSION}

\section{Summary of main results}

The summary below shows the outcomes selected for the Summary of findings for the main comparison and addresses the main findings of this review. 


\section{Service utilisation: hospital readmission}

There was only one study reporting two participants on penfluridol who were readmitted (due to depression). There was no clear differences between the drugs, but this important outcome was only reported in one tiny study $(n=29)$ and data quality have to be considered low. Best evidence highlights no difference. but the best evidence is poor.

\section{Global state}

This is not a difficult outcome to record. No study reported on a binary outcome and the continuous data-measured by Clinical Global Impression (CGI) were unusable (standard deviations of means were not reported in both included studies). No study reported on relapse as the other aspect of global state.

\section{Mental state}

There is, at least, consistency across outcomes. Again, no study reported on a binary outcome and the continuous data were unusable (standard deviations of means were not reported in both included studies). It is easy to unfairly judge pioneering studies of the past by standards of today, but we think it unlikely that the participants in these trials gave informed consent to have data squandered.

\section{Adverse effects/events}

\subsection{Extrapyramidal adverse events-akathisia}

We chose this medium-term outcome because two studies reported on it. Data quality were low, trials were very small (2 RCTs, $N=85$ ) and results equivocal, but there was a suggestion that should studies have been larger, the chlorpromazine group would have experienced less akathisia. Penfluridol, with a relatively higher potency, would be expected to induce more extrapyramidal side effects than chlorpromazine. However, the small sample size and probable reporting bias could mean little difference between the two drugs regarding extrapyramidal adverse effects was observed.

\subsection{Death}

The lifetime incidence of suicide in people with schizophrenia is estimated to be $10 \%$ to $13 \%$ (Caldwell 1992). Sudden death as an adverse effect of antipsychotic drugs has been shown to have an incidence rate ratio of 1.99 (Manu 2011). There was no report of death in the short and small included studies. Of course this is an important effect/event but, in retrospect, it might not have been wise to present this in the 'Summary of findings' as we would always have been unlikely to detect this rare event.

\section{Leaving the study early}

Leaving the study early may be the result of a multitude of reasons including lack of efficacy, adverse effects or an unacceptable study design. All in all, similar numbers of participants left early from each treatment group, neither drug was worse or better than the other. Nearly half of those entered into the studies left or were withdrawn early. On one hand, this could reflect a real-world situation, attrition is often high, but there is the worry that these studies not convincingly reflecting care in routine practice, had any authority they had further eroded by loss to follow-up.

\section{Overall completeness and applicability of evidence}

\section{Completeness}

These are old, small and limited studies. Much data were wasted because of poor reporting and more were never recorded. These are two important drugs and we do not have anywhere near a complete picture of their comparative effects.

\section{Applicability}

Studies in this review included people in both outpatient and inpatient settings. People in the trials were often chronically unwell. This is an important group of people, but not inclusive of everyone with schizophrenia. Trials are also three to four decades old. In many places services have changed considerably in that time, in others, less so. What evidence we have is thin, and its applicability problematic.

\section{Quality of the evidence}

The quality of the current evidence is low, based on ratings generated though GRADE (Schünemann 2011). None of the studies reported how randomisation was achieved and only one trial described the method of allocation concealment. Although studies were reported as double-blinded, none clearly described whether assessors were blinded to the treatment groups. All scale data were reported as means without standard deviations for the main results. Most results were presented in the text with authors simply reporting that results were statistically significant or not, but they did not report statistical measures of probability ( $P$ values) or the confidence interval. Although $P$ values are influenced by the strength of the association, they also depend on the sample size of the groups. It is sometimes possible to extract raw data from $P$ values, but their exact values are needed. In the reviewed studies this was not possible, because they were reported as ' $P<0.05$ ' or 'P $<0.001$ '.

\section{Potential biases in the review process}

\section{Adding the old to the new}

We have found no time-related differences in studies within this review and no indication of change of the effect size over time. Synthesis of the results of studies seems justified.

\section{Failing to identify old trials}

We identified trials by meticulous searching, including handsearching old files. Nevertheless, it may be difficult to avoid some bias from not identifying long-lost studies.

\section{Failing to identify other language trials}

We identified trials in other languages by searching specialist databases. This should have identified, for example, Chinese studies. However, there is always a danger of failing to identify studies and especially if published in languages other than English. It seems unlikely, however, that we have failed to find large important studies.

\section{Agreements and disagreements with other studies or reviews}

To our knowledge, there is no previous review specifically comparing chlorpromazine with penfluridol (Table 1). In another Cochrane study of penfluridol in schizophrenia, penfluridol has 
been suggested to have no significant difference with any other typical antipsychotics in terms of global state, mental state, attrition, and requiring antiparkinsonian medication (Soares 2006). Compared with placebo, chlorpromazine has shown to improve global state and reduce relapse rate and attrition significantly (Adams 2005).

\section{AUTHORS' CONCLUSIONS}

\section{Implications for practice}

\section{For people with schizophrenia}

Although limited data on global state or mental state are available in the included studies of this review, there was no report that chlorpromazine was less effective than penfluridol regarding these outcomes. Needing supplementary antiparkinsonian drugs might be less with chlorpromazine in the medium term.

\section{For clinicians}

There is the suggestion that chlorpromazine may cause less movement disorders than penfluridol, but data are too sparse to be sure. What very few data there are suggests little difference between the two drugs. Penfluridol, however, only needs to be given once per week. This is important and, if there were good data, this long half-life could be useful for some people.

\section{For managers and policy makers}

In situations where these two drugs are accessible, and prescribed, managers and policy makers may wish to encourage randomisation when there is clinical doubt as to which to use. In such a situation real-world randomisation could add much to our knowledge of these drugs.

\section{Implications for research}

\section{General}

We had to exclude Li 1987 due to the poor quality of data reporting, diminishing the already limited evidence-base (please refer to Characteristics of excluded studies for details). Nowadays, following CONSORT (Moher 2001) guidance for reporting of clinical trials would help increase the data available in this review.

\section{Specific}

Even though chlorpromazine has been used in the management of schizophrenia for many years, and penfluridol is also an old drug, high-quality evidence for comparative efficacy and safety is so limited that conducting a well-designed large controlled study is justified where these treatments are still used. We do realise that such studies take meticulous planning but studies reporting clear and routine data have great utility and we suggest a design in Table 2.

\section{ACKNOWLEDGEMENTS}

The Cochrane Schizophrenia Group Editorial Base in Nottingham produces and maintains standard text for use in the Methods section of their reviews. We have used this text as the basis of what appears here and adapted it as required.

The search term was developed by the Information Specialist of the Cochrane Schizophrenia Group and the contact author of this protocol. Jun Xia from Systematic Review Solutions extracted data of Chinese studies. We would like to thank Jamie Majdi and Pippa Shaw for peer reviewing this version of the review.

Parts of this review were generated using RevMan HAL v 4.0. You can find more information about RevMan here. 


\section{RE F E R E N C E S}

\section{References to studies included in this review}

Chouinard 1977 \{published data only\}

Chouinard G, Annable L. Penfluridol in the treatment of newly admitted schizophrenic patients in a brief therapy unit. American Journal of Psychiatry 1976;133(7):850-3. [PUBMED: 937582]

Chouinard G, Annable L, Cooper S. Antiparkinsonian drug administration and plasma levels of penfluridol, a new longacting neuroleptic. Communications in Psychopharmacology 1977;1(4):325-31. [PUBMED: 615695]

* Chouinard G, Annable L, Kolivakis TN. Penfluridol in the maintenance treatment of schizophrenic patients newly discharged from a brief therapy unit. Journal of Clinical Pharmacology 1977;17(2-3):162-7. [PUBMED: 833344]

\section{Claghorn 1979 \{published data only\}}

Claghorn JL, Mathew RJ, Mirabi M. Penfluridol: a long acting oral antipsychotic drug. Journal of Clinical Psychiatry 1979;40(2):107-9. [PUBMED: 368045]

\section{Wang 1982 \{published data only\}}

Wang RI, Larson C, Treul SJ. Study of penfluridol and chlorpromazine in the treatment of chronic schizophrenia. Journal of Clinical Pharmacology 1982;22(5-6):236-42. [PUBMED: 7107969]

\section{References to studies excluded from this review}

Bao 1988 \{published data only\}

Bao XQ. A double-blind study on the effect of clozapine, penfluridol and chlorpromazine in the treatment of schizophrenia. Chinese Journal of Neurology and Psychiatry 1988;21(5):274-6, 318. [PUBMED: 3069382]

\section{Li 1987 \{published data only\}}

Li Y. Application of NOSIE in the study of neuroleptic treatment. Chinese Journal of Neurology and Psychiatry 1987;20(6):325-7. [PUBMED: 3329087]

\section{Additional references}

\section{Adams 2005}

Adams CE, Rathbone J, Thornley B, Clarke M, Borrill J, Wahlbeck K, et al. Chlorpromazine for schizophrenia: a Cochrane systematic review of 50 years of randomised controlled trials. BMC Medicine 2005;3:15. [PUBMED: 16229742]

\section{Adams 2014}

Adams CE, Awad GA, Rathbone J, Thornley B, SoaresWeiser K. Chlorpromazine versus placebo for schizophrenia. Cochrane Database of Systematic Reviews 2014, Issue 1. [DOI: 10.1002/14651858.CD000284.pub3; PUBMED: 24395698]

\section{Ahmed 2010}

Ahmed U, Jones H, Adams CE. Chlorpromazine for psychosis induced aggression or agitation. Cochrane
Database of Systematic Reviews 2010, Issue 4. [DOI: 10.1002/14651858.CD007445.pub2; CD007445]

\section{Almeida-Filho 1997}

Almeida-Filho N, Mari J de J, Coutinho E, Franca JF, Fernandes J, Andreoli SB, et al. Brazilian multicentric study of psychiatric morbidity. Methodological features and prevalence estimates. British Journal of Psychiatry 1997;171(6):524-9. [PUBMED: 9519090]

\section{Almerie 2007}

Almerie MQ, Alkhateeb H, Essali A, Matar HE, Rezk E. Cessation of medication for people with schizophrenia already stable on chlorpromazine. Cochrane Database of Systematic Reviews 2007, Issue 1. [DOI: 10.1002/14651858.CD006329; CD006329]

\section{Altman 1996}

Altman DG, Bland JM. Detecting skewness from summary information. BMJ 1996;313(7066):1200.

\section{Bazrafshan 2015}

Bazrafshan A, Zare M, Okhovati M, Shamsi Meimandi M. Acetophenazine versus chlorpromazine for schizophrenia. Cochrane Database of Systematic Reviews 2015, Issue 4. [DOI: 10.1002/14651858.CD011662]

\section{Bland 1997}

Bland JM. Statistics notes. Trials randomised in clusters. BMJ 1997;315:600.

\section{Boissel 1999}

Boissel JP, Cucherat M, Li W, Chatellier G, Gueyffier F, Buyse $\mathrm{M}$, et al. The problem of therapeutic efficacy indices. 3. Comparison of the indices and their use [Apercu sur la problematique des indices d'efficacite therapeutique, 3 : comparaison des indices et utilisation. Groupe d'Etude des Indices D'efficacite]. Therapie 1999;54(4):405-11. [PUBMED: 10667106]

\section{Caldwell 1992}

Caldwell CB, Gottesman II. Schizophrenia--a high-risk factor for suicide: clues to risk reduction. Suicide and Life-Threatening Behavior 1992;22(4):479-93. [PUBMED: 1488792]

\section{Crow 1980}

Crow TJ. Molecular pathology of schizophrenia: more than one disease process?. British Medical Journal 1980;280(6207):66-8. [PUBMED: 6101544]

\section{Deeks 2000}

Deeks J. Issues in the selection for meta-analyses of binary data. 8th International Cochrane Colloquium; 2000 Oct 25-28; Cape Town. Cape Town: The Cochrane Collaboration, 2000.

\section{Deeks 2011}

Deeks JJ, Higgins JPT, Altman DG, editor(s). Chapter 9: Analysing data and undertaking meta-analyses. In: Higgins JPT, Green S, editor(s). Cochrane Handbook for Systematic Reviews of Interventions Version 5.1.0 (updated March 
2011). The Cochrane Collaboration, 2011. Available from www.handbook.cochrane.org.

\section{Divine 1992}

Divine GW, Brown JT, Frazier LM. The unit of analysis error in studies about physicians' patient care behavior. Journal of General Internal Medicine 1992;7(6):623-9.

\section{Donner 2002}

Donner A, Klar N. Issues in the meta-analysis of cluster randomized trials. Statistics in Medicine 2002;21:2971-80.

\section{Dudley 2009}

Dudley K, Liu X, De Han S. Chlorpromazine dose for people with schizophrenia. Cochrane Database of Systematic Reviews 2017, Issue 4. [DOI: 10.1002/14651858.CD007778.pub2; CD007778]

\section{Egger 1997}

Egger M, Davey Smith G, Schneider M, Minder C. Bias in meta-analysis detected by a simple, graphical test. BMJ 1997;315:629-34.

\section{Elbourne 2002}

Elbourne D, Altman DG, Higgins JPT, Curtina F, Worthington HV, Vaile A. Meta-analyses involving cross-over trials: methodological issues. International Journal of Epidemiology 2002;31(1):140-9.

\section{Eslami 2015}

Eslami Shahrbabaki M, Sharafkhani R, Dehnavieh R, Vali L. Chlorpromazine versus piperacetazine for schizophrenia. Cochrane Database of Systematic Reviews 2015, Issue 6. [DOI: 10.1002/14651858.CD011709]

\section{Fioravanti 2005}

Fioravanti M, Carlone O, Vitale B, Cinti ME, Clare L. A metaanalysis of cognitive deficits in adults with a diagnosis of schizophrenia. Neuropsychology Review 2005;15(2):73-95. [PUBMED: 16211467]

\section{Furukawa 2006}

Furukawa TA, Barbui C, Cipriani A, Brambilla P, Watanabe N. Imputing missing standard deviations in meta-analyses can provide accurate results. Journal of Clinical Epidemiology 2006;59(7):7-10.

\section{Gerlach 1975}

Gerlach J, Kramp P, Kristjansen P, Lauritsen B, Luhdorf K, Munkvad I. Peroral and parenteral administration of long-acting neuroleptics: a double-blind study of penfluridol compared to flupenthixol decanoate in the treatment of schizophrenia. Acta Psychiatrica Scandinavica 1975;52(2):132-44. [PUBMED: 1096541]

\section{Gulliford 1999}

Gulliford MC. Components of variance and intraclass correlations for the design of community-based surveys and intervention studies: data from the Health Survey for England 1994. American Journal of Epidemiology 1999;149:876-83.

\section{Higgins 2003}

Higgins JP, Thompson SG, Deeks JJ, Altman DG. Measuring inconsistency in meta-analyses. BMJ 2003;327:557-60.

\section{Higgins 2011}

Higgins JPT, Green S, editor(s). Chapter 7: Selecting studies and collecting data. In: Higgins JPT, Green S, editor(s), Cochrane Handbook for Systematic Reviews of Interventions Version 5.1.0 (updated March 2011). The Cochrane Collaboration, 2011. Available from www.handbook.cochrane.org.

\section{Higgins 2011a}

Higgins JPT, Altman DG, Sterne JAC, editor(s). Chapter 8: Assessing risk of bias in included studies. In: Higgins JPT, Green S, editor(s). Cochrane Handbook for Systematic Reviews of Interventions Version 5.1.0 (updated March 2011). The Cochrane Collaboration, 2011. Available from www.handbook.cochrane.org.

\section{Hutton 2009}

Hutton JL. Number needed to treat and number needed to harm are not the best way to report and assess the results of randomised clinical trials. British Journal of Haematology 2009;146(1):27-30.

\section{Ionescu 1983}

Ionescu R, Tiberiu C, Miklos R, Angelescu C, Persiceanu AM. Penfluridol in the maintenance therapy of schizophrenia. Neurologie et Psychiatrie 1983;21(1):33-41. [PUBMED: 6342112]

\section{Janssen 1970}

Janssen PA, Niemegeers CJ, Schellekens KH, Lenaerts FM, Verbruggen FJ, Van Nueten JM, et al. The pharmacology of penfluridol (R 16341) a new potent and orally longacting neuroleptic drug. European Journal of Pharmacology 1970;11(2):139-54. [PUBMED: 5447800]

\section{Kay 1986}

Kay SR, Opler LA, Fiszbein A. Positive and Negative Syndrome Scale (PANSS) Manual. North Tonawanda, NY: Multi-Health Systems, 1986.

\section{Leon 2006}

Leon AC, Mallinckrodt CH, Chuang-Stein C, Archibald DG, Archer GE, Chartier K. Attrition in randomized controlled clinical trials: methodological issues in psychopharmacology. Biological Psychiatry 2006;59(11):1001-5. [PUBMED: 16905632]

\section{Leucht 2005a}

Leucht S, Kane JM, Kissling W, Hamann J, Etschel E, Engel R. Clinical implications of brief psychiatric rating scale scores. British Journal of Psychiatry 2005;187:366-71. [PUBMED: 16199797]

\section{Leucht 2005b}

Leucht S, Kane JM, Kissling W, Hamann J, Etschel E, Engel RR. What does the PANSS mean?. Schizophrenia Research 2005;79(2-3):231-8. [PUBMED: 15982856] 


\section{Leucht 2008}

Leucht C, Kitzmantel M, Kane J, Leucht S, Chua WLLC. Haloperidol versus chlorpromazine for schizophrenia. Cochrane Database of Systematic Reviews 2008, Issue 1. [DOI: 10.1002/14651858.CD004278.pub2; CD004278]

\section{Liddle 1987}

Liddle PF. The symptoms of chronic schizophrenia. A reexamination of the positive-negative dichotomy. British Journal of Psychiatry 1987;151:145-51. [PUBMED: 3690102]

\section{Lindstrom 2000}

Lindstrom E, Bingefors K. Patient compliance with drug therapy in schizophrenia. Economic and clinical issues. PharmacoEconomics 2000;18(2):106-24. [PUBMED: 11067646]

\section{Manu 2011}

Manu P, Kane JM, Correll CU. Sudden deaths in psychiatric patients. Journal of Clinical Psychiatry 2011;72(7):936-41. [PUBMED: 21672496]

\section{Marshall 2000}

Marshall M, Lockwood A, Bradley C, Adams C, Joy C, Fenton M. Unpublished rating scales: a major source of bias in randomised controlled trials of treatments for schizophrenia. British Journal of Psychiatry 2000;176:249-52.

\section{Moher 2001}

Moher D, Schulz KF, Altman DG. The CONSORT statement: revised recommendations for improving the quality of reports of parallel group randomized trials. BMC Medical Research Methodology 2001;1:2. [PUBMED: 11336663]

\section{Overall 1962}

Overall JE, Gorham DR. The brief psychiatric rating scale. Psychological Reports 1962;10:799-812.

\section{Perala 2007}

Perala J, Suvisaari J, Saarni SI, Kuoppasalmi K, Isometsa E, Pirkola S, et al. Lifetime prevalence of psychotic and bipolar I disorders in a general population. Archives of General Psychiatry 2007;64(1):19-28. [PUBMED: 17199051]

\section{Rees 1960}

Rees L. Chlorpromazine and allied phenothiazine derivatives. British Medical Journal 1960;2(5197):522-5. [PUBMED: 14436902]

\section{Reynolds 1982}

Reynolds JEM. Penfluridol. Martindale: The Extra Pharmacopoeia. 28th Edition. London: The Pharmaceutical Press, 1982:1550.

\section{Saha 2013}

Saha KB, Bo L, Zhao S, Xia J, Sampson S, Zaman RU. Chlorpromazine versus atypical antipsychotic drugs for schizophrenia. Cochrane Database of Systematic Reviews 2016, Issue 4. [DOI: 10.1002/14651858.CD010631.pub2]

\section{Schünemann 2011}

Schünemann HJ, Oxman AD, Vist GE, Higgins JPT, Deeks JJ, Glasziou P, et al. Chapter 12: Interpreting results and drawing conclusions. In Higgins JPT, Green S editor(s), Cochrane Handbook for Systematic Reviews of Interventions Version 5.1.0 (updated March 2011). The Cochrane Collaboration, 2011. Available from www.cochrane-handbook.org.

\section{Soares 2006}

Soares BG, Silva de Lima M. Penfluridol for schizophrenia. Cochrane Database of Systematic Reviews 2006, Issue 2. [DOI: 10.1002/14651858.CD002923.pub2; PUBMED: 16625563]

\section{Sterne 2011}

Sterne JAC, Egger M, Moher D, editor(s). Chapter 10: Addressing reporting biases. In: Higgins JPT, Green S, editor(s). Cochrane Handbook for Systematic Reviews of Intervention. Version 5.1.0 (updated March 2011). The Cochrane Collaboration, 2011. Available from www.handbook.cochrane.org.

\section{Ukoumunne 1999}

Ukoumunne OC, Gulliford MC, Chinn S, Sterne JAC, Burney PGJ. Methods for evaluating area-wide and organisation-based intervention in health and health care: a systematic review. Health Technology Assessment 1999;3(5):1-75.

\section{van Praag 1971}

van Praag HM, Schut T, Dols L, van Schilfgaarden R. Controlled trial of penfluridol in acute psychosis. British Medical Journal 1971;4(5789):710-3. [PUBMED: 4943034]

\section{WHO 2015}

World Health Organization. 19th WHO Essential Medicines List. www.who.int/medicines/publications/essentialmedicines/en/ (accessed prior to 25 May 2017).

\section{Xia 2009}

Xia J, Adams CE, Bhagat N, Bhagat V, Bhoopathi P, El-Sayeh H, et al. Loss to outcomes stakeholder survey: the LOSS study. Psychiatric Bulletin 2009;33(7):254-7.

\section{Zare 2015}

Zare M, Bazrafshan A. Chlorpromazine versus metiapine for schizophrenia. Cochrane Database of Systematic Reviews 2017, Issue 3. [DOI: 10.1002/14651858.CD011655.pub2]

\section{References to other published versions of this review \\ Khalili 2005}

Khalili N, Vahedian M, Nikvarz N, Piri M. Chlorpromazine versus penfluridol for schizophrenia. Cochrane Database of Systematic Reviews 2015, Issue 8. [DOI: 10.1002/14651858.CD011831]

* Indicates the major publication for the study 
CHARACTERISTICS OF STUDIES

Characteristics of included studies [ordered by study ID]

Chouinard 1977

\begin{tabular}{|c|c|}
\hline Methods & $\begin{array}{l}\text { Allocation: randomised. } \\
\text { Blindness: double-blind. } \\
\text { Location: inpatient and outpatient. } \\
\text { Duration: } 13 \text { weeks ( } 3 \text { weeks inpatient, } 10 \text { weeks outpatient). }\end{array}$ \\
\hline Participants & $\begin{array}{l}\text { Diagnosis: schizophrenia (DSM-II). } \\
\mathrm{N}=33 \text {. } \\
\text { Age: } 19-60 \text { years ( mean } 35.7 \pm 12.6 \text { ). } \\
\text { Sex: } 15 \mathrm{M} \text { and } 14 \mathrm{~F}^{\star} \text {. } \\
\text { History: } 15 \text { participants had been hospitalised for less than a year. }\end{array}$ \\
\hline Interventions & $\begin{array}{l}\text { 1. Chlorpromazine: oral - } 300 \mathrm{mg} / \text { day the first week, } 600 \mathrm{mg} / \text { day second week, and } 900 \mathrm{mg} / \mathrm{day} \text { third } \\
\text { week. } \mathrm{N}=19 .^{\star \star} \\
\text { 2. Penfluridol: oral }-40 \mathrm{mg} / \text { day the first week, } 80 \mathrm{mg} / \text { day second week, and } 120 \mathrm{mg} / \text { day third week. } \mathrm{N}= \\
\text { 14. }{ }^{\star \star}\end{array}$ \\
\hline Outcomes & $\begin{array}{l}\text { Adverse events: general (needing antiparkinson medication, reduction in antipsychotic dose due to } \\
\text { side effects, specific (extrapyramidal and various other effects). } \\
\text { Leaving the study early. } \\
\text { Unable to use - } \\
\text { Global state: average score/change CGI (no data). } \\
\text { Need for additional medication: not outcome prespecified in protocol. } \\
\text { Mental state: average score/change BPRS and IMPS (no SD). }\end{array}$ \\
\hline
\end{tabular}

Notes

* 4 participants left early during inpatient phase-not included in follow-up analyses at 13 weeks.

\section{Risk of bias}

\begin{tabular}{lll}
\hline Bias & Authors' judgement & Support for judgement \\
\hline $\begin{array}{l}\text { Random sequence genera- } \\
\text { tion (selection bias) }\end{array}$ & Low risk & $\begin{array}{l}\text { "Subjects were assigned to one of two evaluating psychiatrists in such a way } \\
\text { that each psychiatrist evaluated a group that included both male and female } \\
\text { patients, permitting the examination of a possible sex effect. Individuals in } \\
\text { each group were randomly assigned to one of the two drug treatments, pen- } \\
\text { fluridol or chlorpromazine, which were administered under double-blind con- } \\
\text { ditions". }\end{array}$ \\
\hline $\begin{array}{l}\text { Allocation concealment } \\
\text { (selection bias) }\end{array}$ & Unclear risk & No description regarding allocation concealment. \\
\hline $\begin{array}{l}\text { Blinding of participants } \\
\text { and personnel (perfor- } \\
\text { mance bias) } \\
\begin{array}{l}\text { All outcomes } \\
\hline\end{array}\end{array}$ & Unclear risk & Described as double blind-no further details reported. \\
\hline
\end{tabular}


Chouinard 1977 (Continued)

Blinding of outcome as- Unclear risk No details about blinding of outcome assessment given "Assessment of sympsessment (detection bias) toms was based on clinical interviews conducted by one of the two psychiaAll outcomes trists, the same psychiatrist always evaluating the same group of patients".

Incomplete outcome data Low risk Attrition low and clearly described.

(attrition bias)

All outcomes

Selective reporting (re- Unclear risk All outcomes reported, but poor reporting of scale data.

porting bias)

Other bias Unclear risk Source of funding not reported.

\section{Claghorn 1979}

$\begin{array}{ll}\text { Methods } & \text { Allocation: randomised. } \\ \text { Blindness: double-blind. } \\ \text { Location: inpatient. } \\ \text { Duration: } 52 \text { weeks. }\end{array}$

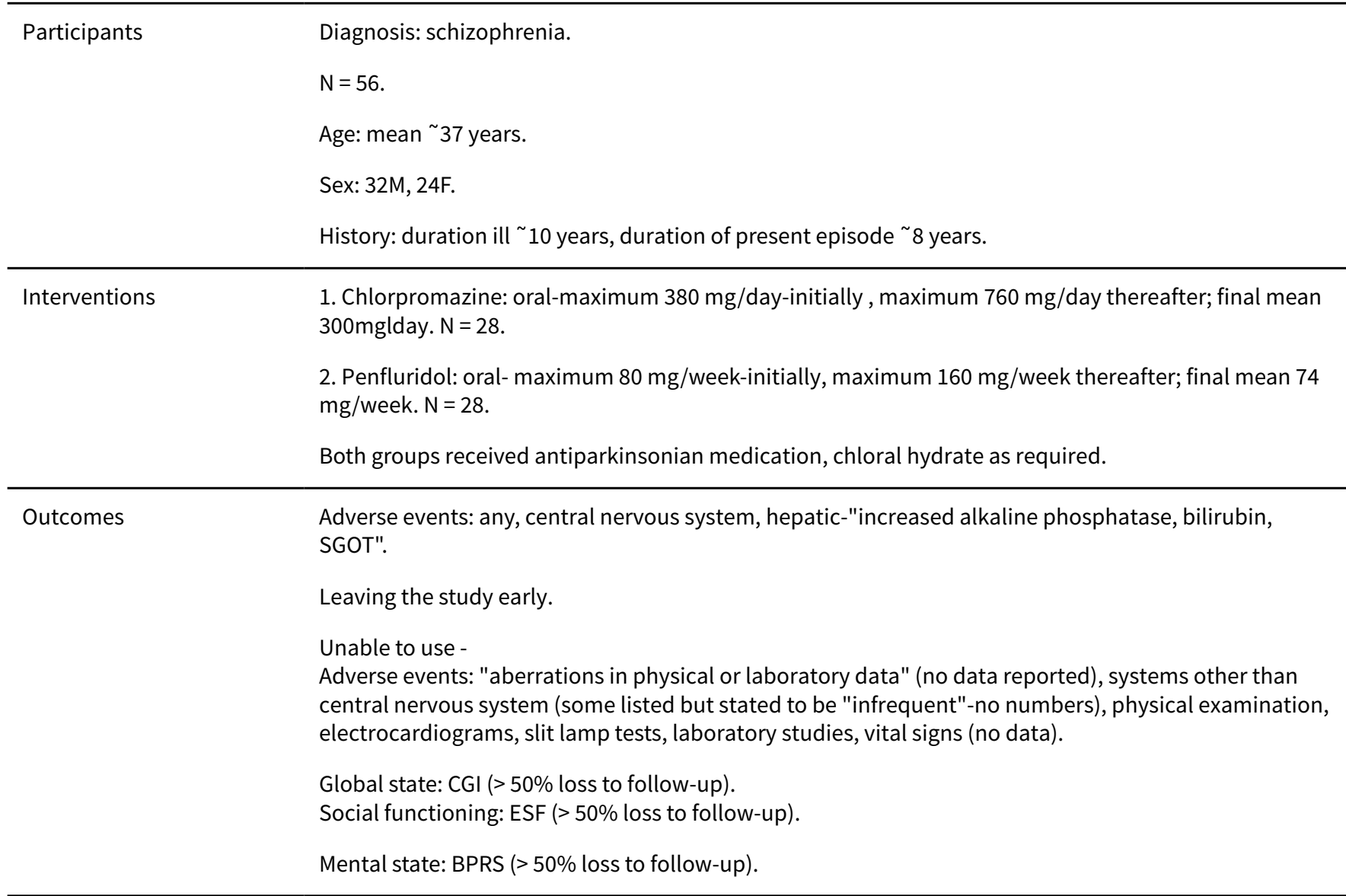

Notes

\section{Risk of bias}


Claghorn 1979 (Continued)

\begin{tabular}{lll} 
Bias & Authors' judgement & Support for judgement \\
\hline $\begin{array}{l}\text { Random sequence genera- } \\
\text { tion (selection bias) }\end{array}$ & Low risk & ..."randomly assigned in blocks of 8 or $10 "$. \\
\hline $\begin{array}{l}\text { Allocation concealment } \\
\text { (selection bias) }\end{array}$ & Unclear risk & No description regarding allocation concealment.
\end{tabular}

(selection bias)

\begin{tabular}{|c|c|c|}
\hline $\begin{array}{l}\text { Blinding of participants } \\
\text { and personnel (perfor- }\end{array}$ & Unclear risk & $\begin{array}{l}\text { Described as "double blind"-placebo tablet given to penfluridol group to cover } \\
\text { non-drug days. No further details reported. }\end{array}$ \\
\hline
\end{tabular}
non-drug days. No further details reported.

mance bias)

All outcomes

\begin{tabular}{ll}
\hline Blinding of outcome as- & Unclear risk details about blinding of outcome assessment. \\
sessment (detection bias) &
\end{tabular}

All outcomes

Incomplete outcome data Unclear risk $\quad$ Attrition high but clearly described.
(attrition bias)

All outcomes

\begin{tabular}{|c|c|c|}
\hline $\begin{array}{l}\text { Selective reporting (re- } \\
\text { porting bias) }\end{array}$ & High risk & $\begin{array}{l}\text { Adverse effects mostly reported if frequent (unclear how frequent), poor re- } \\
\text { porting of scale data. }\end{array}$ \\
\hline
\end{tabular}

\begin{tabular}{ll}
\hline Other bias $\quad$ Unclear risk $\quad$ Source of funding not reported. \\
\hline
\end{tabular}

Wang 1982

\begin{tabular}{|c|c|}
\hline Methods & $\begin{array}{l}\text { Allocation: randomised. } \\
\text { Blindness: double blind. } \\
\text { Location: inpatient. } \\
\text { Duration: } 20 \text { weeks. }\end{array}$ \\
\hline Participants & $\begin{array}{l}\text { Diagnosis: schizophrenia. } \\
\mathrm{N}=41 \text { (double-blind phase).* } \\
\text { Age: } 20-60 \text { years. } \\
\text { Sex: all male. } \\
\text { History: chronic schizophrenia for at least } 18 \text { months prior to the start of the study. } \\
\text { Excluded: all participants were stabilised on penfluridol before the trial, participants who did not com- } \\
\text { plete dose titration were excluded before randomisation. }\end{array}$ \\
\hline
\end{tabular}

Interventions 1. Chlorpromazine: oral ( $150 \mathrm{mg} /$ day to $1050 \mathrm{mg} /$ day). $\mathrm{N}=20$.

1. Penfluridol: oral ( $20 \mathrm{mg}$ to $140 \mathrm{mg}$ once a week). $\mathrm{N}=21$.

Outcomes

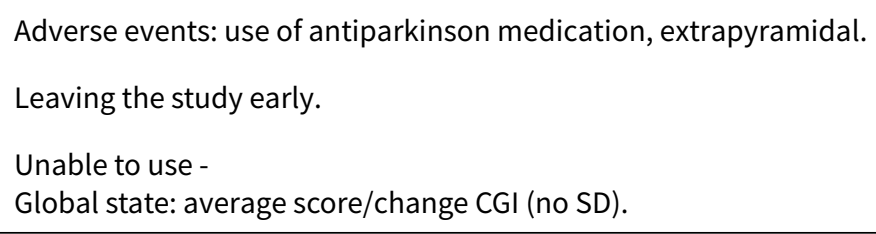


Wang 1982 (Continued)

Use of additional antipsychotic: not outcome prespecified in protocol.

Mental state: average score/change BPRS (no SD).

Behaviour: average score/change NOSIE (no SD).

Social functioning: average score/change ESF (no SD).

\section{Notes}

Trial had a dose titration phase where all participants stabilised on penfluridol and a double-blind phase where participants randomised to continue penfluridol or switch to chlorpromazine, we only used data from the double-blind phase.

It is indicated in the paper that there were no statistical differences in scale-derived data, and that patients on penfluridol had more akathisia than patients on chlorpromazine, but no data presented.

\section{Risk of bias}

\begin{tabular}{|c|c|c|}
\hline Bias & Authors' judgement & Support for judgement \\
\hline $\begin{array}{l}\text { Random sequence genera- } \\
\text { tion (selection bias) }\end{array}$ & Low risk & $\begin{array}{l}\text { "When the patients were stable, they were randomly assigned to a penfluridol } \\
\text { or a chlorpromazine group". }\end{array}$ \\
\hline $\begin{array}{l}\text { Allocation concealment } \\
\text { (selection bias) }\end{array}$ & Unclear risk & No details regarding allocation concealment given. \\
\hline $\begin{array}{l}\text { Blinding of participants } \\
\text { and personnel (perfor- } \\
\text { mance bias) } \\
\text { All outcomes }\end{array}$ & Low risk & $\begin{array}{l}\text { "All patients received identical appearing capsules on a special "blister pack" } \\
\text { medication card allowing the patient to take the medication on a twice-a-day } \\
\text { schedule". }\end{array}$ \\
\hline $\begin{array}{l}\text { Blinding of outcome as- } \\
\text { sessment (detection bias) } \\
\text { All outcomes }\end{array}$ & Unclear risk & $\begin{array}{l}\text { Not clear if outcome assessor was blind-"The rating scales for evaluating effi- } \\
\text { cacy ...... were completed by the psychiatrist investigator". }\end{array}$ \\
\hline $\begin{array}{l}\text { Incomplete outcome data } \\
\text { (attrition bias) } \\
\text { All outcomes }\end{array}$ & Low risk & Attrition low and clearly described. \\
\hline $\begin{array}{l}\text { Selective reporting (re- } \\
\text { porting bias) }\end{array}$ & Unclear risk & All outcomes reported, but poor reporting of scale data. \\
\hline Other bias & Unclear risk & No further details. \\
\hline
\end{tabular}

BPRS-Brief Psychiatric Rating Scale

CGI-Clinical Global Impression

ESF-Evaluation of Social Functioning

IMPS: Inpatient Multidimensional Psychiatric Scale

NOSIE-Nurse's Observation Scale for Inpatient Evaluation

SD: standard deviation

SGOT: serum glutamic oxaloacetic transaminase

Characteristics of excluded studies [ordered by study ID]

\begin{tabular}{ll}
\hline Study & Reason for exclusion \\
\hline Bao 1988 & Allocation: quasi-randomised. \\
\hline Li 1987 & Allocation: randomised. \\
Participants: people with schizophrenia.
\end{tabular}


DATA AND ANALYSES

Comparison 1. CHLORPROMAZINE versus PENFLURIDOL

\begin{tabular}{|c|c|c|c|c|}
\hline Outcome or subgroup title & No. of studies & $\begin{array}{l}\text { No. of partici- } \\
\text { pants }\end{array}$ & Statistical method & Effect size \\
\hline $\begin{array}{l}1 \text { Service utilisation: } 1 \text {. Hospital } \\
\text { readmission }\end{array}$ & 1 & 29 & Risk Ratio (M-H, Fixed, 95\% Cl) & $0.19[0.01,3.60]$ \\
\hline 1.1 short term & 1 & 29 & Risk Ratio (M-H, Fixed, 95\% Cl) & $0.19[0.01,3.60]$ \\
\hline $\begin{array}{l}2 \text { Adverse effects: } 1 \text { a. General - } \\
\text { needing antiparkinsonian med- } \\
\text { ication }\end{array}$ & 2 & 74 & Risk Ratio (M-H, Fixed, 95\% Cl) & $0.70[0.51,0.95]$ \\
\hline 2.1 short term & 1 & 33 & Risk Ratio (M-H, Fixed, 95\% Cl) & $0.82[0.46,1.46]$ \\
\hline 2.2 medium term & 1 & 41 & Risk Ratio (M-H, Fixed, 95\% Cl) & $0.63[0.43,0.91]$ \\
\hline $\begin{array}{l}3 \text { Adverse effects: } 1 \text { b. General } \\
\text { - need to reduce antipsychotic } \\
\text { dose due to side effects }\end{array}$ & 1 & & Risk Ratio (M-H, Fixed, 95\% Cl) & Subtotals only \\
\hline 3.1 medium term & 1 & 33 & Risk Ratio (M-H, Fixed, 95\% Cl) & $0.74[0.26,2.06]$ \\
\hline $\begin{array}{l}4 \text { Adverse effects: } 2 \text { a. Specific - } \\
\text { extrapyramidal events (moder- } \\
\text { ate or severe) - short term }\end{array}$ & 1 & & Risk Ratio (M-H, Fixed, 95\% Cl) & Subtotals only \\
\hline 4.1 akatisia & 1 & 33 & Risk Ratio (M-H, Fixed, 95\% Cl) & $0.0[0.0,0.0]$ \\
\hline 4.2 dyskinesia & 1 & 33 & Risk Ratio (M-H, Fixed, 95\% Cl) & $0.0[0.0,0.0]$ \\
\hline 4.3 dystonia & 1 & 33 & Risk Ratio (M-H, Fixed, 95\% Cl) & $0.0[0.0,0.0]$ \\
\hline 4.4 rigidity & 1 & 33 & Risk Ratio (M-H, Fixed, 95\% Cl) & $0.15[0.01,2.90]$ \\
\hline 4.5 tremor & 1 & 33 & Risk Ratio (M-H, Fixed, 95\% Cl) & $0.0[0.0,0.0]$ \\
\hline $\begin{array}{l}5 \text { Adverse effects: } 2 \text { b. Specific - } \\
\text { extrapyramidal events (moder- } \\
\text { ate or severe) - medium term }\end{array}$ & 3 & & Risk Ratio (M-H, Fixed, 95\% Cl) & Subtotals only \\
\hline 5.1 akathisia & 2 & 85 & Risk Ratio (M-H, Fixed, 95\% Cl) & $0.19[0.04,1.06]$ \\
\hline 5.2 dyskinesia & 2 & 85 & Risk Ratio (M-H, Fixed, 95\% Cl) & $0.97[0.14,6.52]$ \\
\hline
\end{tabular}




\begin{tabular}{|c|c|c|c|c|}
\hline Outcome or subgroup title & No. of studies & $\begin{array}{l}\text { No. of partici- } \\
\text { pants }\end{array}$ & Statistical method & Effect size \\
\hline 5.3 dystonia & 1 & 29 & Risk Ratio (M-H, Fixed, 95\% Cl) & $0.93[0.06,13.54]$ \\
\hline 5.4 muscle spasm & 1 & 56 & Risk Ratio (M-H, Fixed, 95\% Cl) & $3.0[0.13,70.64]$ \\
\hline 5.5 rigidity & 2 & 70 & Risk Ratio (M-H, Fixed, 95\% Cl) & $0.22[0.04,1.20]$ \\
\hline 5.6 tremor & 2 & 85 & Risk Ratio (M-H, Fixed, 95\% Cl) & $0.70[0.14,3.43]$ \\
\hline $\begin{array}{l}6 \text { Adverse effects: } 2 c \text {. Specific - } \\
\text { anticholinergic (moderate or se- } \\
\text { vere) - short term }\end{array}$ & 1 & & Risk Ratio (M-H, Fixed, 95\% Cl) & Subtotals only \\
\hline 6.1 constipation & 1 & 33 & Risk Ratio (M-H, Fixed, 95\% Cl) & $4.42[0.60,32.71]$ \\
\hline 6.2 dry mouth & 1 & 33 & Risk Ratio (M-H, Fixed, 95\% Cl) & $2.25[0.10,51.46]$ \\
\hline 6.3 increased salivation & 1 & 33 & Risk Ratio (M-H, Fixed, 95\% Cl) & $0.25[0.01,5.72]$ \\
\hline $\begin{array}{l}7 \text { Adverse effects: } 2 d \text {. Specific - } \\
\text { anticholinergic (moderate or se- } \\
\text { vere) - medium term }\end{array}$ & 1 & & Risk Ratio (M-H, Fixed, 95\% Cl) & Subtotals only \\
\hline 7.1 blurred vision & 1 & 29 & Risk Ratio (M-H, Fixed, 95\% Cl) & $0.31[0.01,7.09]$ \\
\hline 7.2 constipation & 1 & 29 & Risk Ratio (M-H, Fixed, 95\% Cl) & $3.73[0.47,29.49]$ \\
\hline 7.3 dry mouth & 1 & 29 & Risk Ratio (M-H, Fixed, 95\% Cl) & $2.81[0.12,63.83]$ \\
\hline $\begin{array}{l}8 \text { Adverse effects: } 2 \text { e. Specific - } \\
\text { central nervous system (moder- } \\
\text { ate or severe) - short term }\end{array}$ & 1 & & Risk Ratio (M-H, Fixed, 95\% Cl) & Subtotals only \\
\hline 8.1 agitation & 1 & 33 & Risk Ratio (M-H, Fixed, 95\% Cl) & $2.25[0.10,51.46]$ \\
\hline 8.2 drowsiness & 1 & 33 & Risk Ratio (M-H, Fixed, 95\% Cl) & $8.25[0.49,137.94]$ \\
\hline 8.3 dizziness & 1 & 33 & Risk Ratio (M-H, Fixed, 95\% Cl) & $0.25[0.03,2.12]$ \\
\hline 8.4 insomnia & 1 & 33 & Risk Ratio (M-H, Fixed, 95\% Cl) & $2.25[0.10,51.46]$ \\
\hline $\begin{array}{l}9 \text { Adverse effects: } 2 \text { f. Specific - } \\
\text { central nervous system (moder- } \\
\text { ate or severe) - medium term }\end{array}$ & 2 & & Risk Ratio (M-H, Fixed, 95\% Cl) & Subtotals only \\
\hline 9.1 drowsiness & 2 & 85 & Risk Ratio (M-H, Fixed, 95\% Cl) & $1.05[0.54,2.05]$ \\
\hline 9.2 dizziness & 1 & 29 & Risk Ratio (M-H, Fixed, 95\% Cl) & $0.47[0.05,4.60]$ \\
\hline 9.3 excitement & 1 & 29 & Risk Ratio (M-H, Fixed, 95\% Cl) & $2.81[0.12,63.83]$ \\
\hline 9.4 faintness & 1 & 29 & Risk Ratio (M-H, Fixed, 95\% Cl) & $0.93[0.15,5.76]$ \\
\hline 9.5 insomnia & 2 & 85 & Risk Ratio (M-H, Fixed, 95\% Cl) & $0.17[0.03,0.93]$ \\
\hline
\end{tabular}




\begin{tabular}{|c|c|c|c|c|}
\hline Outcome or subgroup title & No. of studies & $\begin{array}{l}\text { No. of partici- } \\
\text { pants }\end{array}$ & Statistical method & Effect size \\
\hline $\begin{array}{l}10 \text { Adverse effects: } 2 \text { g. Specific - } \\
\text { various other effects (moderate } \\
\text { or severe) - short term }\end{array}$ & 2 & & Risk Ratio (M-H, Fixed, 95\% Cl) & Subtotals only \\
\hline 10.1 heartburn & 1 & 33 & Risk Ratio (M-H, Fixed, 95\% Cl) & $0.0[0.0,0.0]$ \\
\hline $\begin{array}{l}10.2 \text { increased alkaline phos- } \\
\text { phatase, bilirubin, SGOT }\end{array}$ & 1 & 56 & Risk Ratio (M-H, Fixed, 95\% Cl) & $0.33[0.01,7.85]$ \\
\hline 10.3 systemic allergic reaction & 1 & 33 & Risk Ratio (M-H, Fixed, 95\% Cl) & $5.25[0.29,94.14]$ \\
\hline $\begin{array}{l}11 \text { Adverse effects: } 2 \text { h. Specific - } \\
\text { various other effects (moderate } \\
\text { or severe) - medium term }\end{array}$ & 1 & & Risk Ratio (M-H, Fixed, 95\% Cl) & Subtotals only \\
\hline 11.1 depression & 1 & 29 & Risk Ratio (M-H, Fixed, 95\% Cl) & $0.19[0.01,3.60]$ \\
\hline 11.2 decreased sexual drive & 1 & 29 & Risk Ratio (M-H, Fixed, 95\% Cl) & $0.47[0.05,4.60]$ \\
\hline 11.3 impotence & 1 & 29 & Risk Ratio (M-H, Fixed, 95\% Cl) & $2.81[0.12,63.83]$ \\
\hline 11.4 photosensitivity & 1 & 29 & Risk Ratio (M-H, Fixed, 95\% Cl) & $2.81[0.12,63.83]$ \\
\hline 11.5 poor appetite & 1 & 29 & Risk Ratio (M-H, Fixed, 95\% Cl) & $0.93[0.06,13.54]$ \\
\hline $\begin{array}{l}12 \text { Leaving the study early: } 1 \mathrm{a} \text {. } \\
\text { Any reason }\end{array}$ & 3 & & Risk Ratio (M-H, Fixed, 95\% Cl) & Subtotals only \\
\hline 12.1 medium term & 3 & 130 & Risk Ratio (M-H, Fixed, 95\% Cl) & $1.21[0.83,1.77]$ \\
\hline $\begin{array}{l}13 \text { Leaving the study early: } 1 \mathrm{~b} \text {. } \\
\text { Due to adverse events }\end{array}$ & 2 & & Risk Ratio (M-H, Fixed, 95\% Cl) & Subtotals only \\
\hline 13.1 short term & 1 & 33 & Risk Ratio (M-H, Fixed, 95\% Cl) & $6.75[0.39,116.00]$ \\
\hline 13.2 medium term & 2 & 74 & Risk Ratio (M-H, Fixed, 95\% Cl) & $1.53[0.72,3.28]$ \\
\hline
\end{tabular}

Analysis 1.1. Comparison 1 CHLORPROMAZINE versus PENFLURIDOL, Outcome 1 Service utilisation: 1. Hospital readmission.

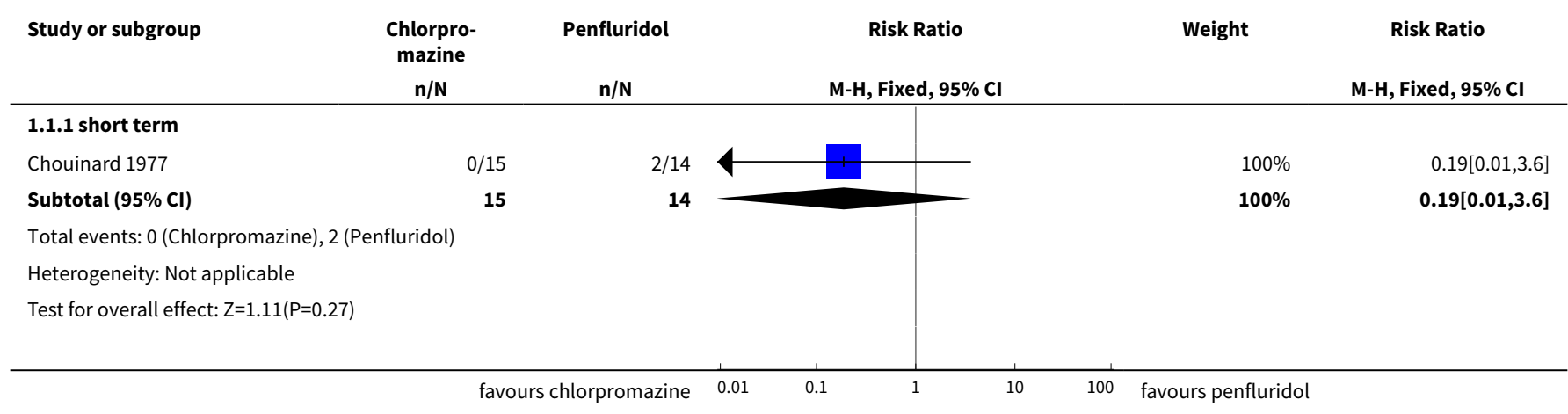




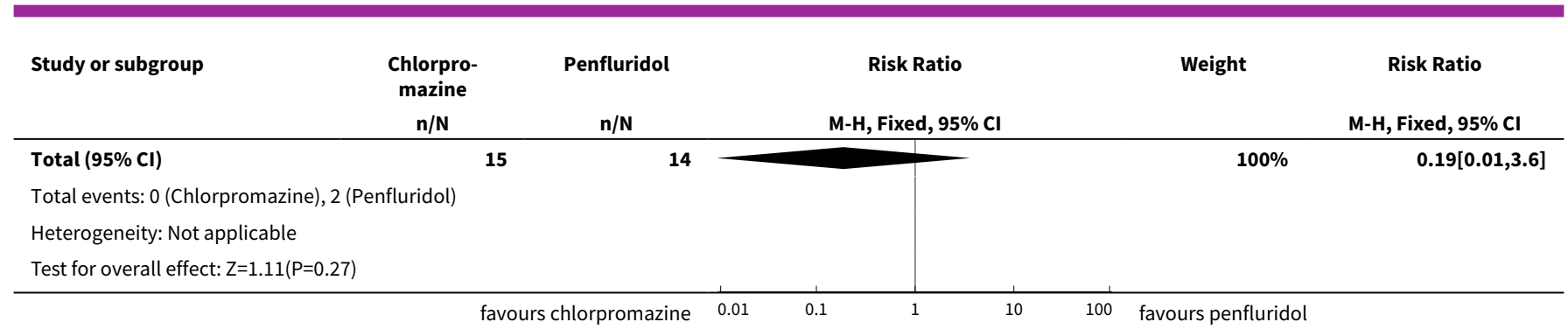

Analysis 1.2. Comparison 1 CHLORPROMAZINE versus PENFLURIDOL, Outcome 2 Adverse effects: 1a. General - needing antiparkinsonian medication.

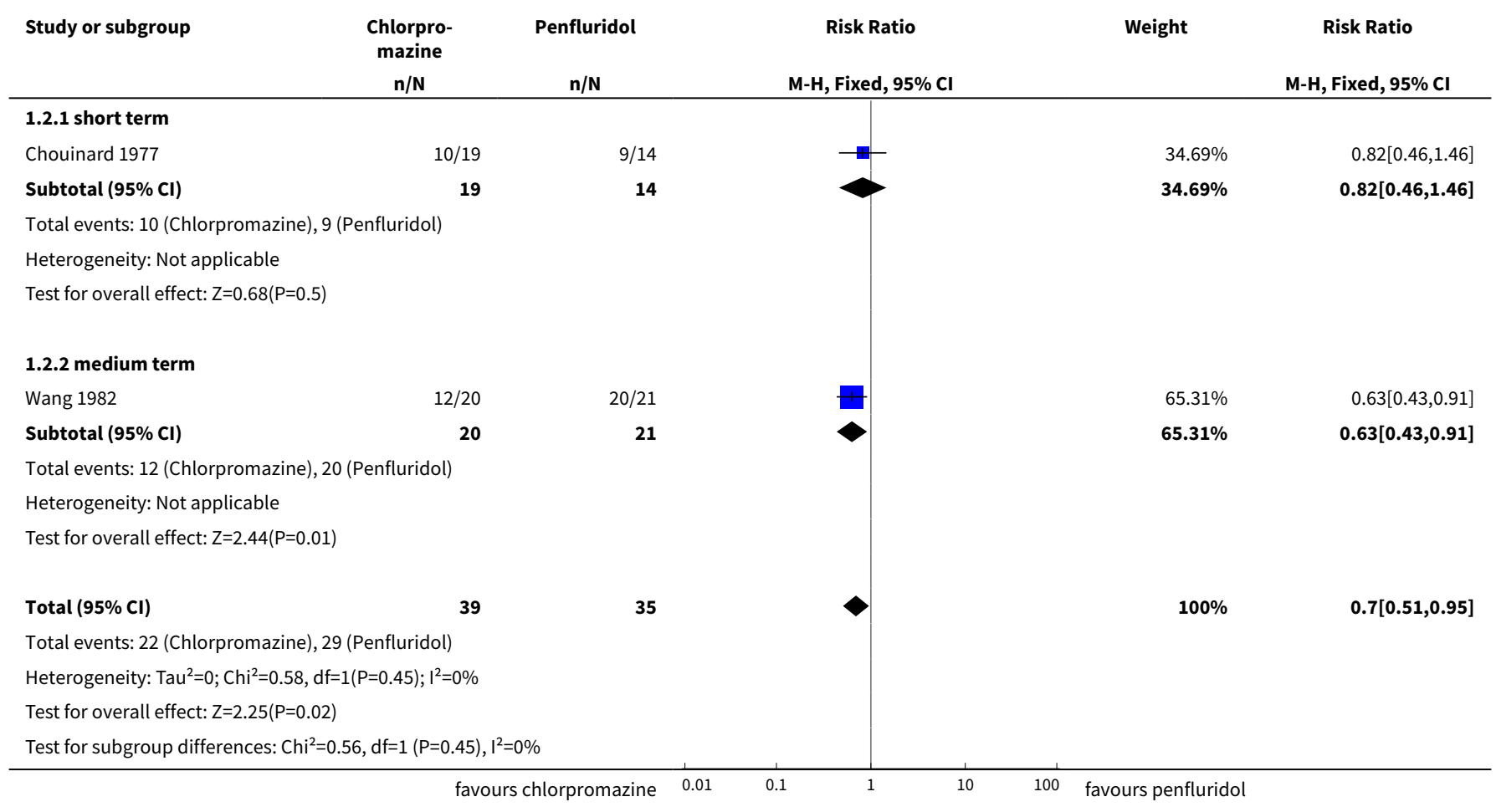

Analysis 1.3. Comparison 1 CHLORPROMAZINE versus PENFLURIDOL, Outcome 3 Adverse effects: 1b. General - need to reduce antipsychotic dose due to side effects.

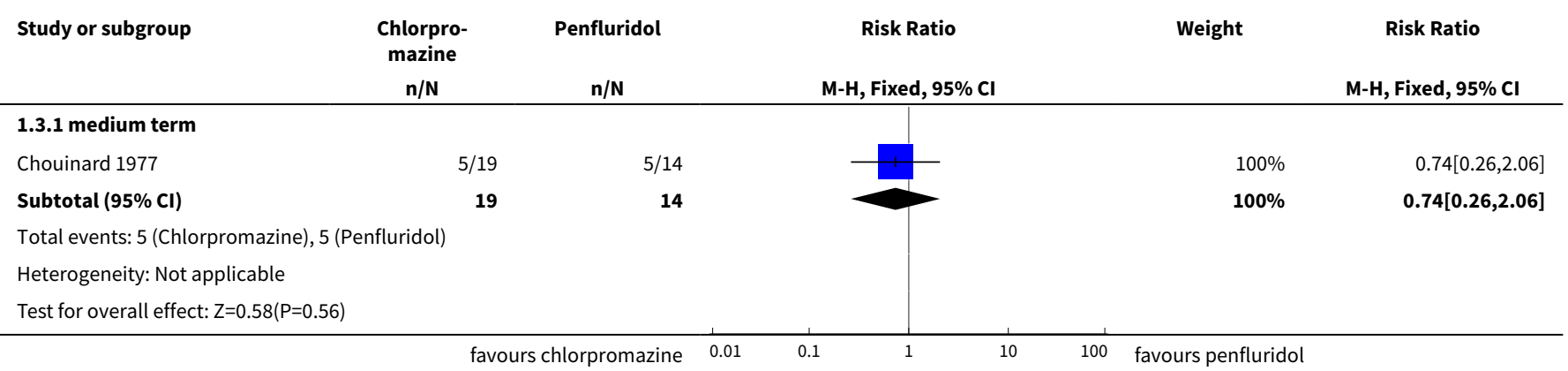


Analysis 1.4. Comparison 1 CHLORPROMAZINE versus PENFLURIDOL, Outcome 4 Adverse effects: $2 a$. Specific - extrapyramidal events (moderate or severe) - short term.

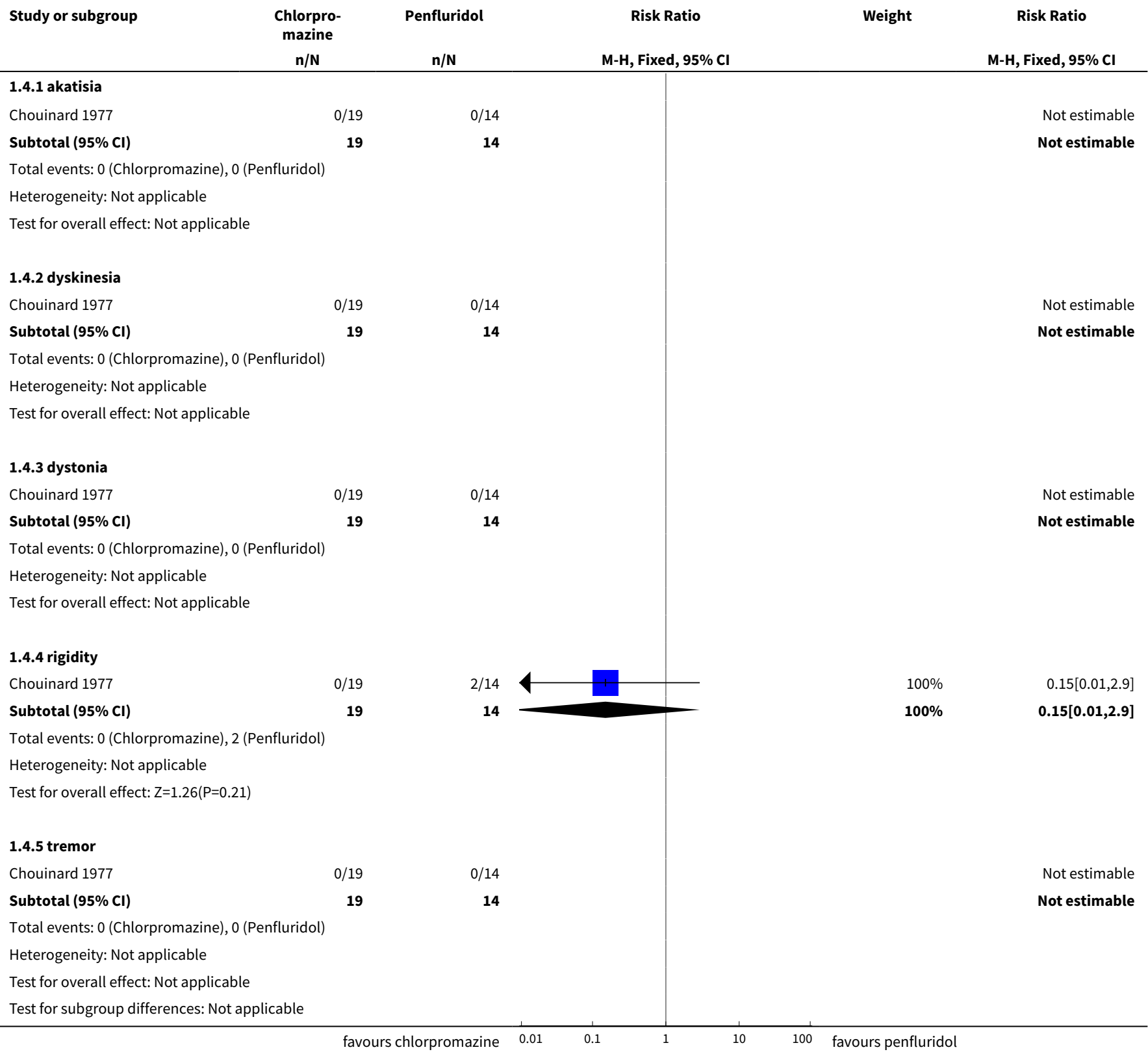

Analysis 1.5. Comparison 1 CHLORPROMAZINE versus PENFLURIDOL, Outcome 5 Adverse effects: 2 b. Specific - extrapyramidal events (moderate or severe) - medium term.

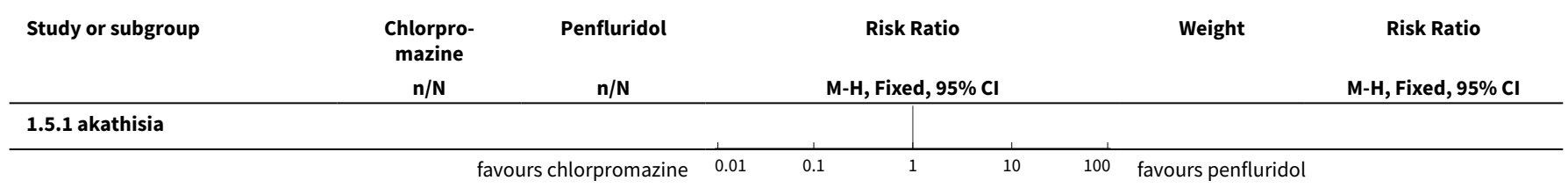




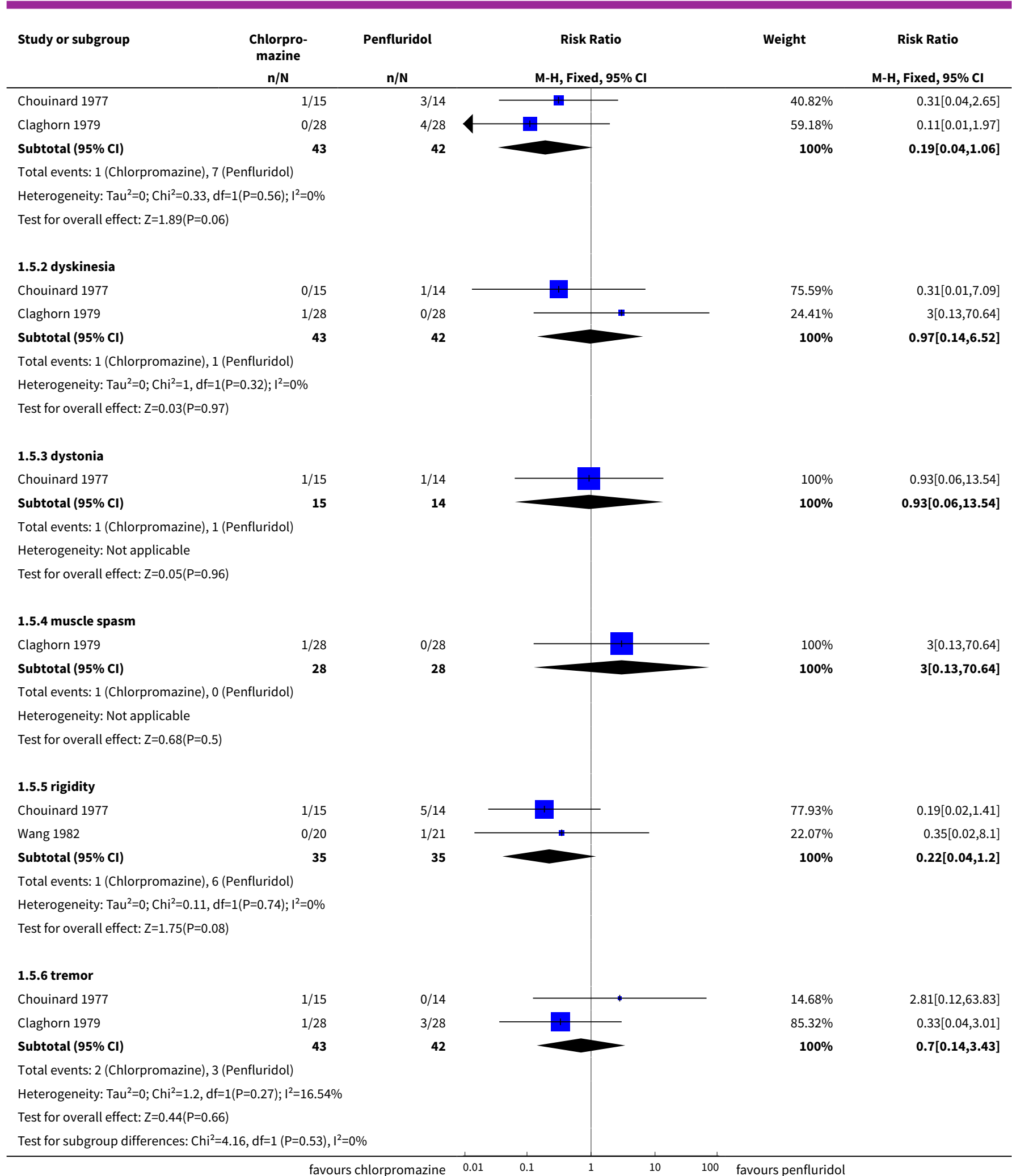


Analysis 1.6. Comparison 1 CHLORPROMAZINE versus PENFLURIDOL, Outcome 6 Adverse effects: $2 c$. Specific - anticholinergic (moderate or severe) - short term.

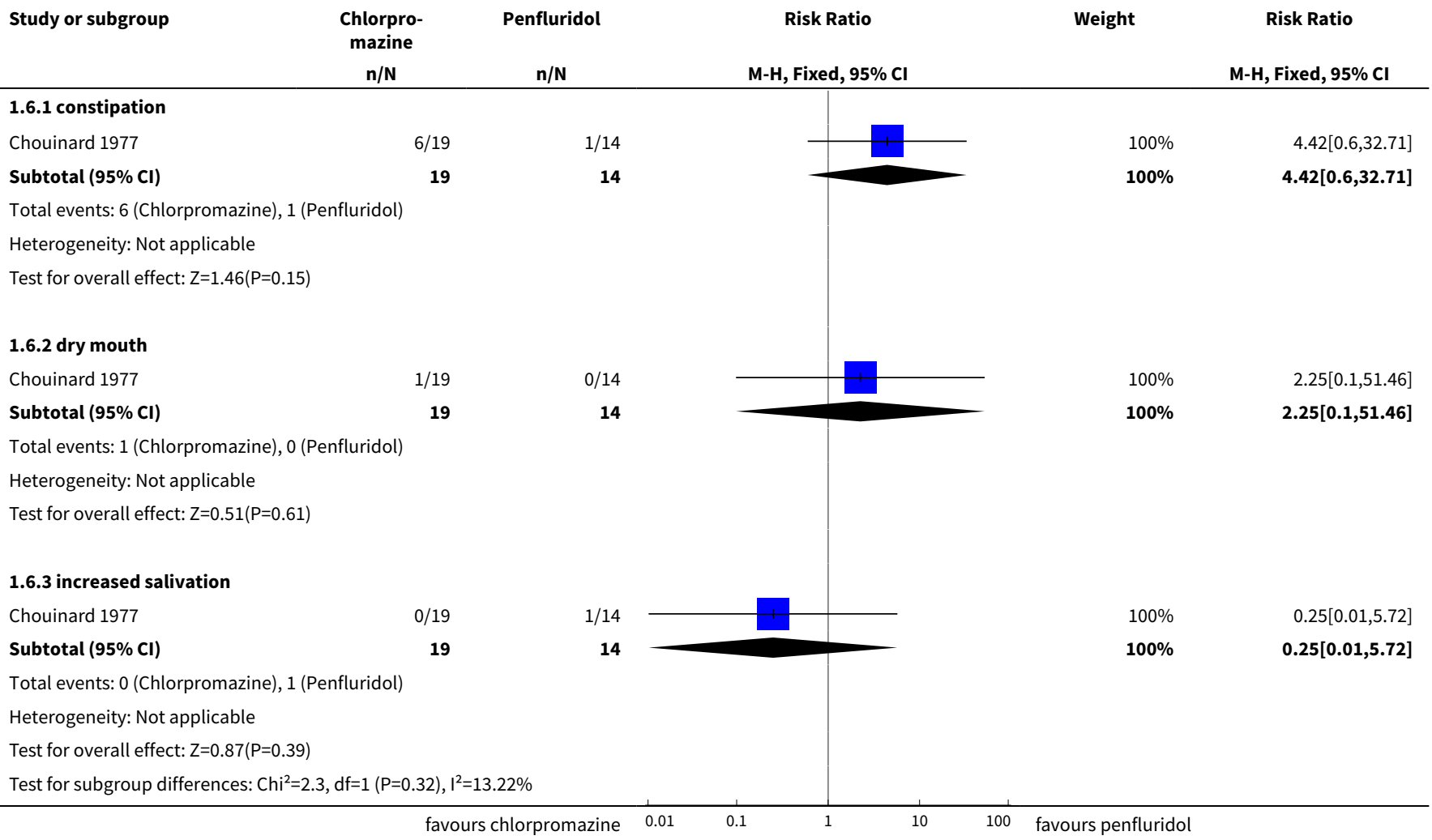

Analysis 1.7. Comparison 1 CHLORPROMAZINE versus PENFLURIDOL, Outcome 7 Adverse effects: 2d. Specific - anticholinergic (moderate or severe) - medium term.

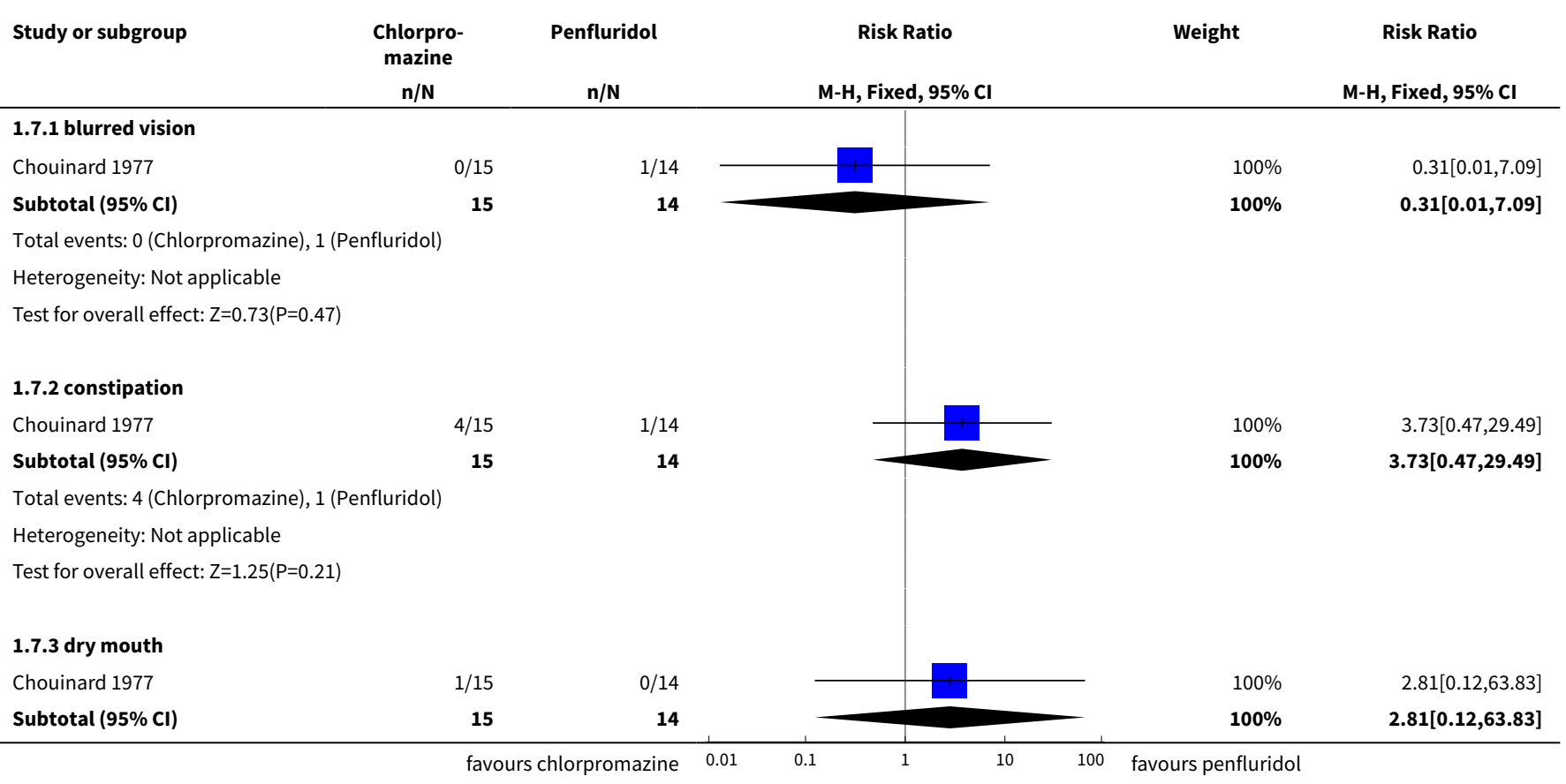




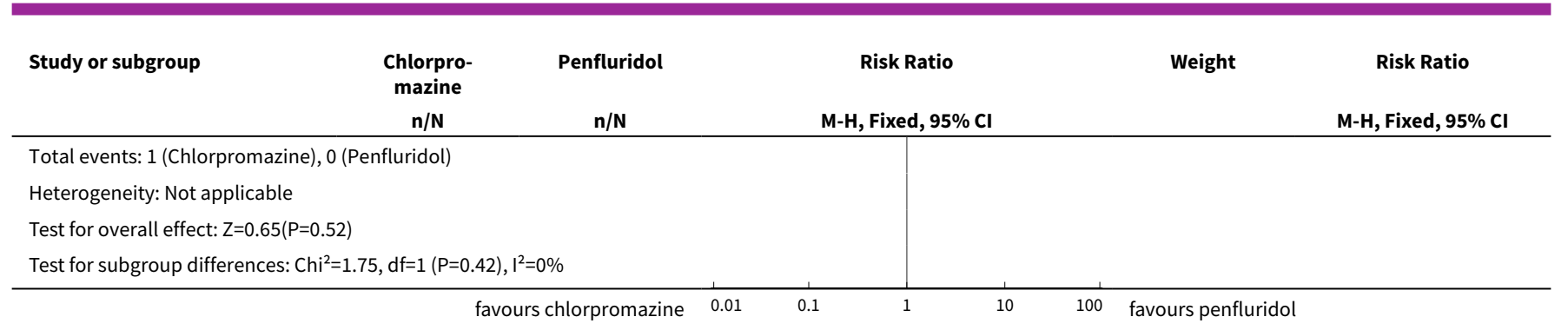

Analysis 1.8. Comparison 1 CHLORPROMAZINE versus PENFLURIDOL, Outcome 8 Adverse effects: 2 e. Specific - central nervous system (moderate or severe) - short term.

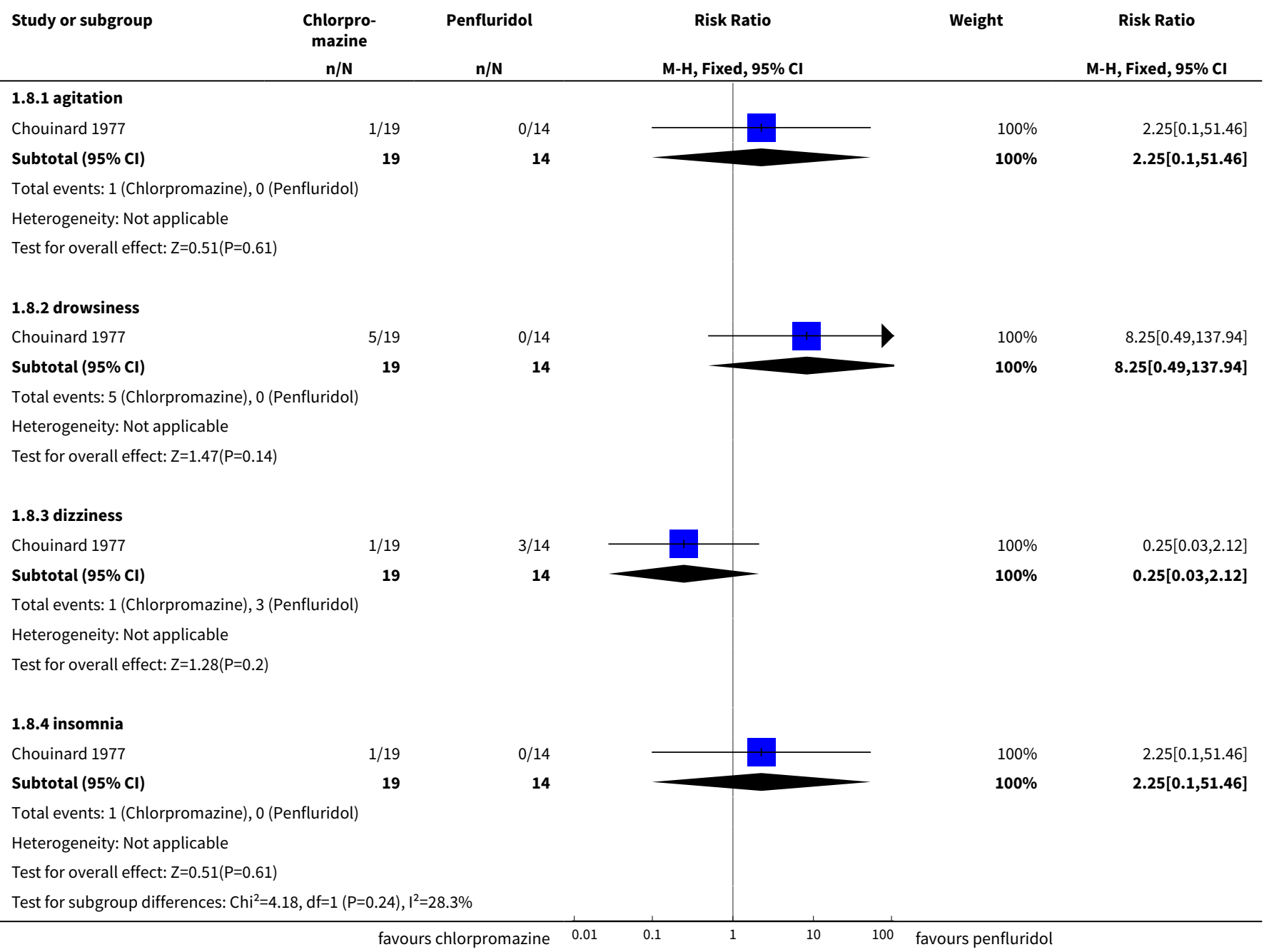


Analysis 1.9. Comparison 1 CHLORPROMAZINE versus PENFLURIDOL, Outcome 9 Adverse effects: 2f. Specific - central nervous system (moderate or severe) - medium term.

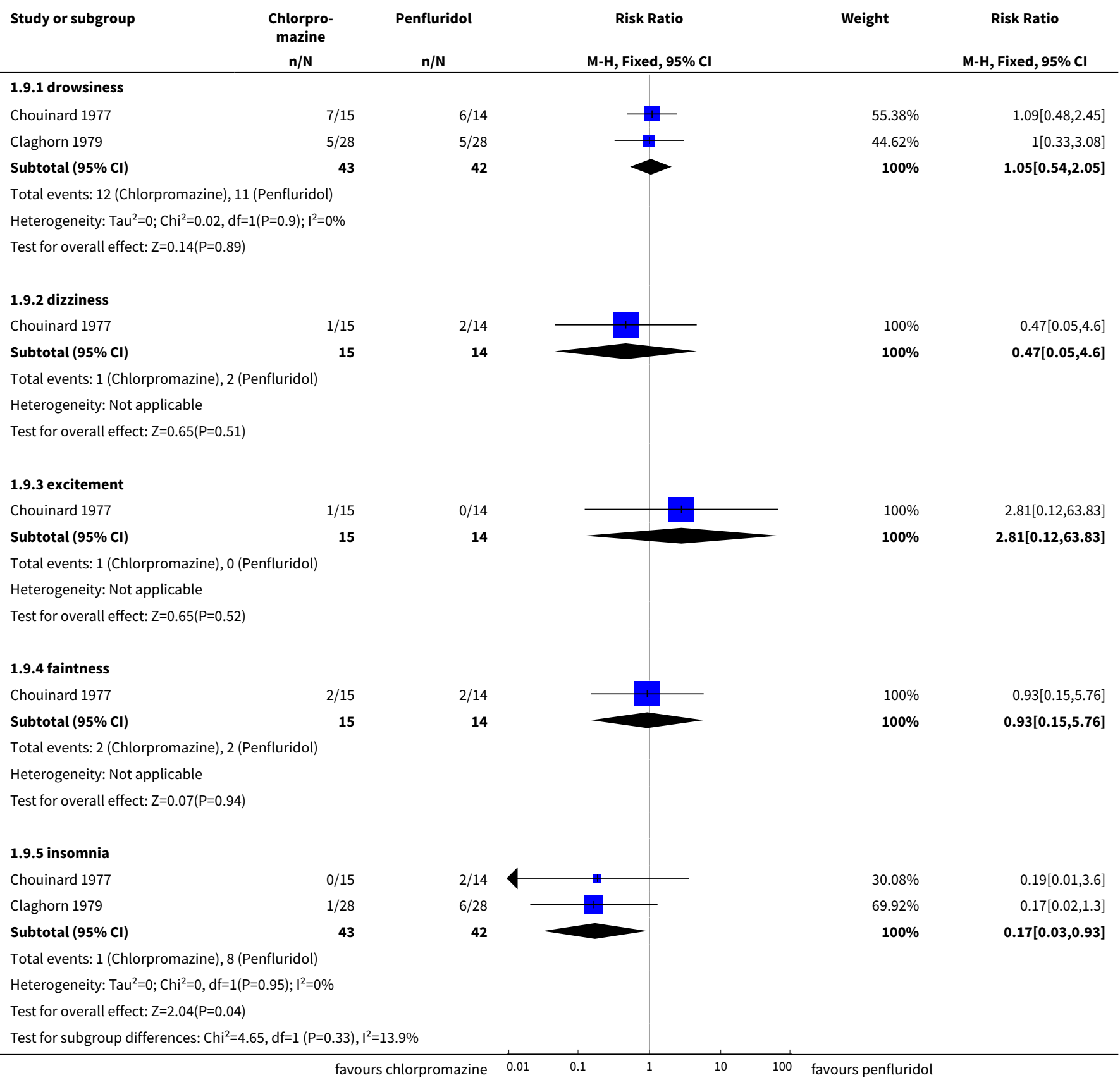

Analysis 1.10. Comparison 1 CHLORPROMAZINE versus PENFLURIDOL, Outcome 10 Adverse effects: $2 \mathrm{~g}$. Specific - various other effects (moderate or severe) - short term.

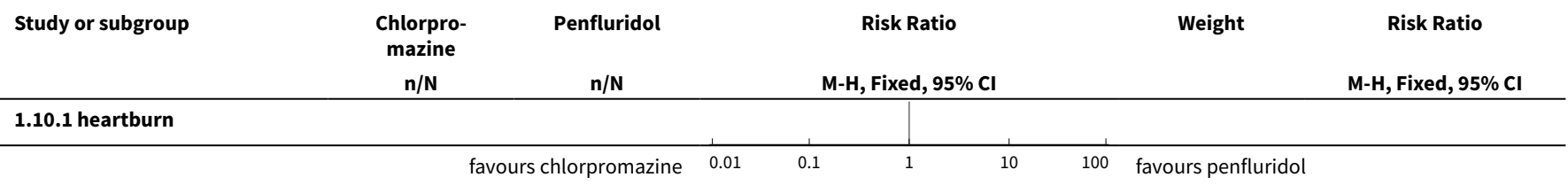




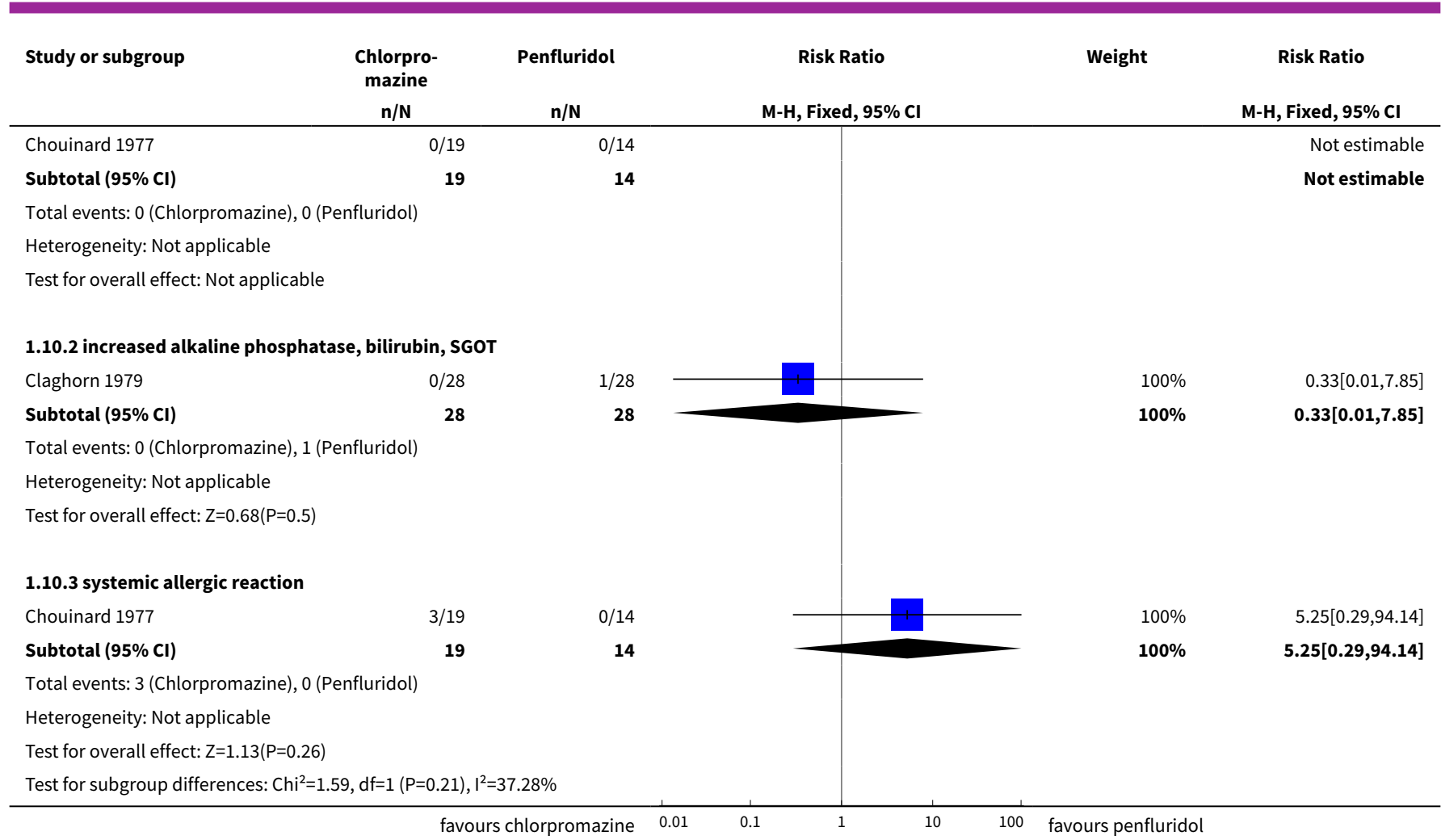

Analysis 1.11. Comparison 1 CHLORPROMAZINE versus PENFLURIDOL, Outcome 11 Adverse effects: $2 \mathrm{~h}$. Specific - various other effects (moderate or severe) - medium term.

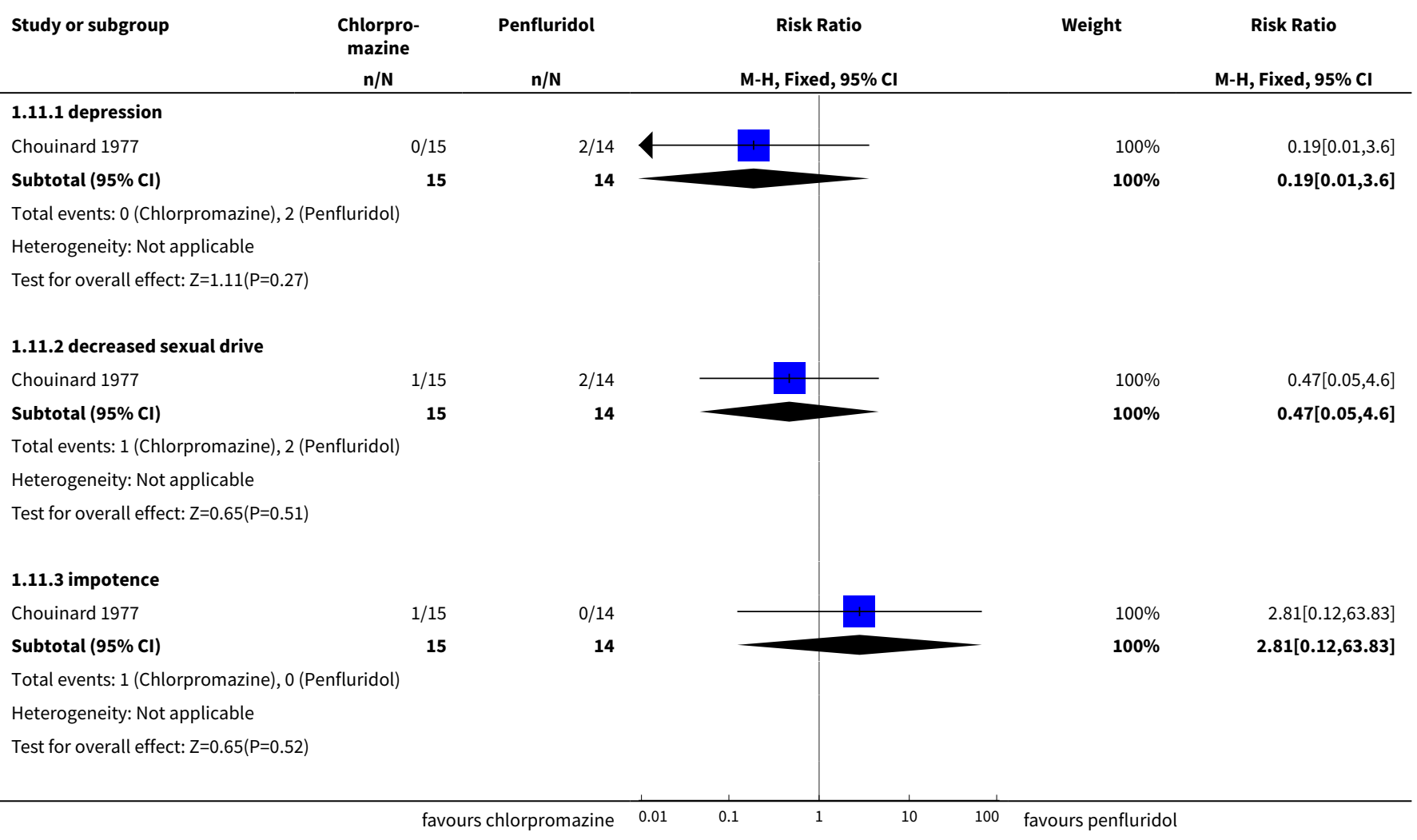




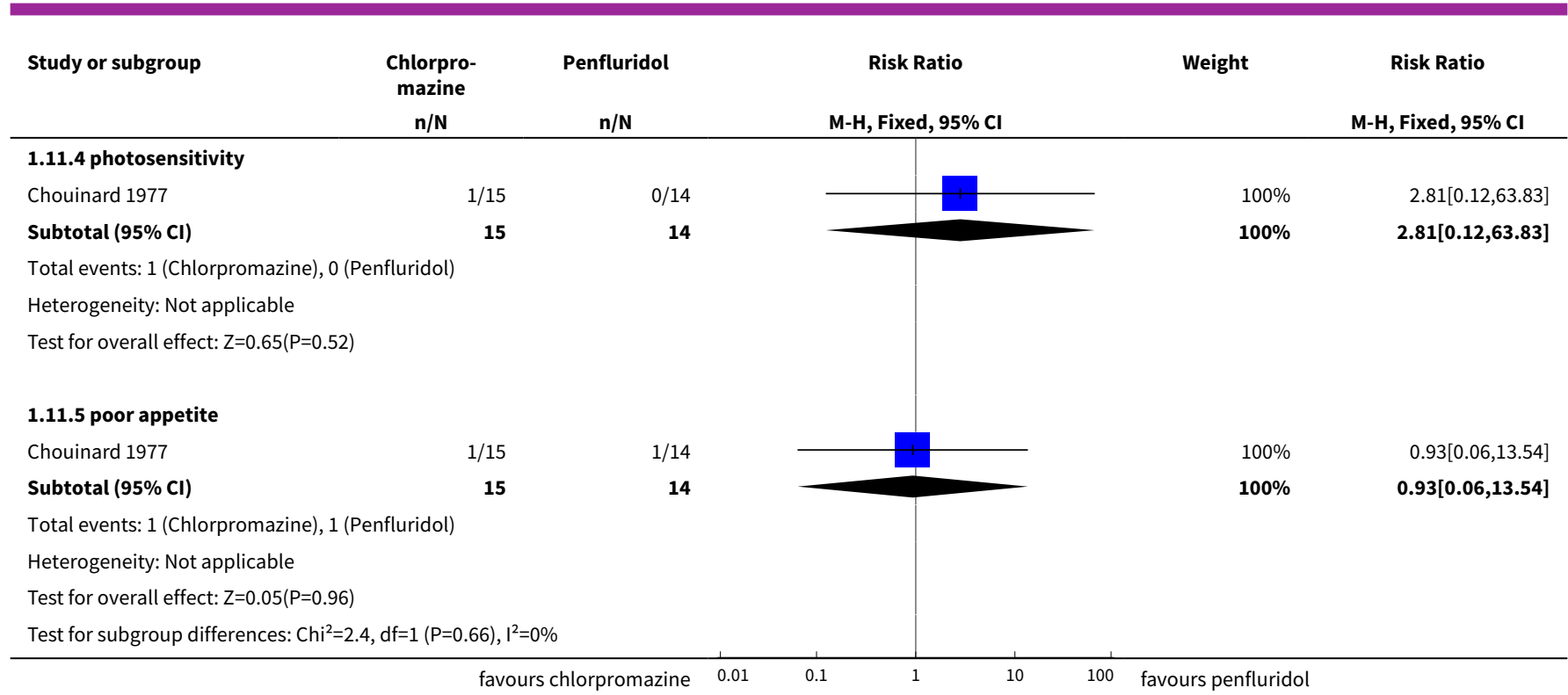

Analysis 1.12. Comparison 1 CHLORPROMAZINE versus PENFLURIDOL, Outcome 12 Leaving the study early: 1a. Any reason.

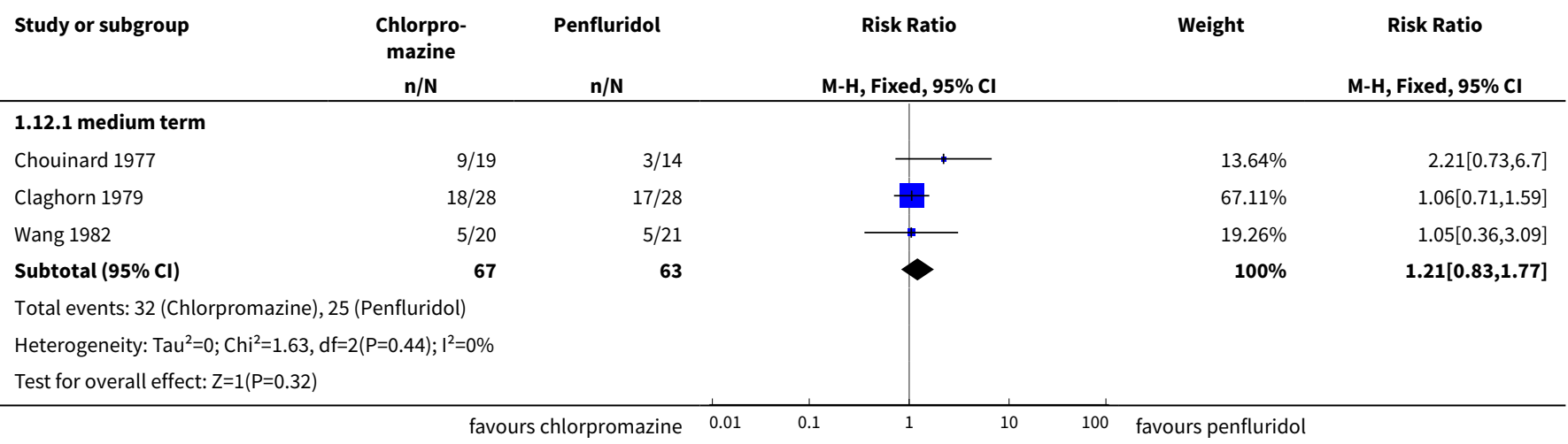

Analysis 1.13. Comparison 1 CHLORPROMAZINE versus PENFLURIDOL, Outcome 13 Leaving the study early: $1 \mathrm{~b}$. Due to adverse events.

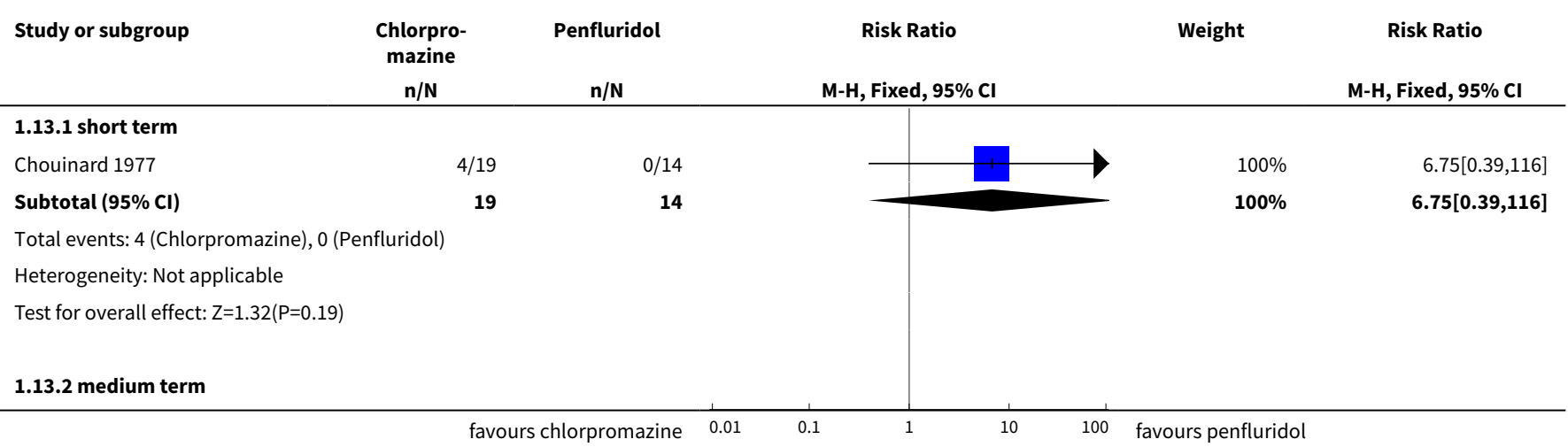




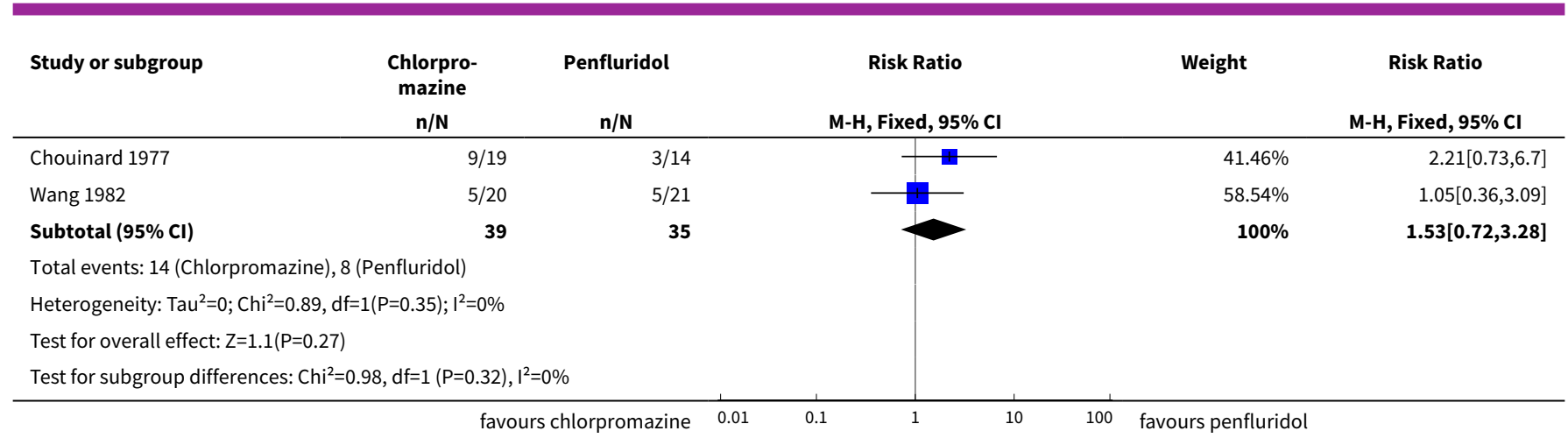

\section{ADDITIONAL TABLES}

Table 1. Cochrane reviews on chlorpromazine for people with schizophrenia

\begin{tabular}{ll}
\hline Review title & Reference \\
\hline Acetophenazine versus chlorpromazine & Bazrafshan 2015 \\
\hline Chlorpromazine dose for people with schizophrenia & Dudley 2009 \\
\hline Cessation of medication for people with schizophrenia already stable on chlorpromazine & Almerie 2007 \\
\hline Chlorpromazine versus atypical antipsychotic drugs for schizophrenia & Saha 2013 \\
\hline Chlorpromazine versus clotiapine for schizophrenia & Developing protocol \\
\hline Chlorpromazine versus haloperidol for schizophrenia & Leucht 2008 \\
\hline Chlorpromazine versus metiapine & Zare 2015 \\
\hline Chlorpromazine versus penfluridol for schizophrenia & Current review \\
\hline Chlorpromazine versus piperacetazine & Eslami 2015 \\
\hline Chlorpromazine versus placebo for schizophrenia & Adams 2014 \\
\hline Chlorpromazine for psychosis induced aggression or agitation & Ahmed 2010
\end{tabular}

\section{Table 2. Suggested design of study}

\begin{tabular}{ll}
\hline Methods & Allocation: randomised, fully explicit description of methods of randomisation and allocation con- \\
cealment. & Blinding: single-blind or double-blind, but tested. \\
& Setting: anywhere. \\
& Duration: follow-up to at least 52 weeks. \\
\hline Participants & Diagnosis: schizophrenia. \\
& N = 300.* \\
Age: adults. \\
Sex: both.
\end{tabular}


Table 2. Suggested design of study (Continued)
Interventions
1. Chlorpromazine: oral-maximum around $400 \mathrm{mg} /$ day. $\mathrm{N}=150$.
2. Penfluridol: oral-maximum around $80 \mathrm{mg} /$ week. $\mathrm{N}=150$.
Both groups could receive antiparkinsonian medication as required.

Service utilisation: Hospital admission, time to admission.
Global state: Clinically significant response in global state, relapse.
Mental state: Clinically significant response in mental state.
Adverse effects: Clinically significant extrapyramidal side effects, death.
Leaving the study early.
Functioning: Employed, days working, in supportive relationship, healthy days.
Economic outcomes.

\section{HIS T O R Y}

Protocol first published: Issue 8, 2015

Review first published: Issue 9, 2017

\begin{tabular}{lll}
\hline Date & Event & Description \\
\hline 31 March 2017 & Amended & Search was updated and no new results were found. \\
\hline
\end{tabular}

\section{CONTRIBUTIONS OF AUTHORS}

Navid Khalili: Wrote the protocol, discussed allocation of responsibility for the tasks, selection of studies, data extraction, edited the Cochrane Schizophrenia Group template for the methods section, contributed in entering data in the Review Manager (RevMan) software, substantially contributed in writing and completing the primary draft of the manuscript and read and approved the final version of the review.

Mostafa Vahedian: Discussed allocation of responsibility for the tasks, selection of studies, data extraction, edited the Cochrane Schizophrenia Group template for the methods section, contributed in entering data in RevMan substantially contributed in writing and completing the primary draft of the manuscript and read and approved the final version of the review.

Naemeh Nikvarz: Discussed allocation of responsibility for the tasks, selection of studies, data extraction, contributed in entering data in RevMan and Grade profiler software, substantially contributed in writing and completing the primary draft of the manuscript and critically revised it and read and approved the final version of the review.

\section{DECLARATIONS OF INTEREST}

NK: No conflict of interest.

MV: No conflict of interest.

NN: No conflict of interest. 


\section{SOURCES OF SUPPORT}

\section{Internal sources}

- Kerman University of Medical Sciences, Kerman, Iran.

Employs lead author Naemeh Nikvarz and review author Navid Khalili. Review author Mostafa Vahedian is a student at this university.

\section{External sources}

- No sources of support supplied

\section{DIFFERENCES BETWEEN PROTOCOLAND REVIEW}

We have reworded and regrouped the outcomes to more closely reflect the latest Cochrane Schizophrenia Group's methods template. Originally, the outcome of the adverse event/effect of death was the first outcome on our preferred 'Summary of fIndings' list. This seemed to strike an unfortunate, unwanted and inaccurate emphasis and for the full review we reordered outcomes.

\section{INDEX TERMS}

\section{Medical Subject Headings (MeSH)}

Akathisia, Drug-Induced [epidemiology]; Antipsychotic Agents [adverse effects] [ ${ }^{\star}$ therapeutic use]; Chlorpromazine [adverse effects] [^therapeutic use]; Length of Stay; Penfluridol [adverse effects] [therapeutic use]; Randomized Controlled Trials as Topic; Schizophrenia [ ${ }^{*}$ drug therapy]

\section{MeSH check words}

Adult; Humans 